\title{
School Entry Cutoff Dates and the Timing of Births
}

Hitoshi Shigeoka ${ }^{1}$

First draft: Feb 15, 2013

Current version: April 21, 2013

\section{Preliminary draft - Comments welcome - Do not cite without permission}

\begin{abstract}
This is the first paper that documents that school entry cut-off date affects the timing of births. Many countries require children to reach a certain age by a specified date in the calendar year in order to start primary school. There is a clear tradeoff for parents to time a birth either before or after the school entry cut-off date; births just before cut-off date benefit parents by avoiding a year of child care costs through sending their children to school at a relatively young age, while births just after cut-off date may benefit children from being in the oldest among the school cohort, which is shown to provide the children with academic advantage. Using the universe of birth during 1974-2010 in Japan, I find that more than 1,800 births per year are shifted roughly a week before the cut-off date to a week following the cut-off date. The overall shifts in births, however, mask heterogeneous responses of mothers. I find that non-working mothers are more likely to delay births than working mothers. Also male births and higher parity births are more likely to be delayed. Interestingly among those working mothers, mothers with low skilled jobs are more likely to shift births before the school entry cut-off dates, suggesting that for those mothers financial burden of child care outweighs the importance of future academic advantage of children. This study may have implications for growing literature that assumes births around the school entry cut-off dates are random.
\end{abstract}

Acknowledgement:

This project is supported by a research grant from the Ministry of Health, Labour and Welfare (H22-policy-033, Principle Investigator: Kenji Shibuya and co-investigator: Hideki Hashimoto). The use of data in this paper is approved by Ministry of Health, Labour and Welfare under this grant. I thank Meltem Daysal, Pilar García-Gómez, Hideki Hashimoto, Adriana Lleras-Muney, Andrew McGee, Asako Ohinata, Kjell Salvanes, and seminar participants as Erasmus University, Simon Fraser University, and Tilburg University for their suggestions and comments. Takashi Unayama kindly shared the data for public day-care centers. All errors are my own.

\footnotetext{
${ }^{1}$ Department of Economics, Simon Fraser University, 8888 University Drive, WMC 4653, Burnaby, BC, V5A 1S6, Canada. E-mail Address: hitoshi_shigeoka@sfu.ca Tel: +1-778-782-5348
} 


\section{Introduction}

A growing body of literature relies on the identification strategy that assumes that births around the school entry cut-off dates are random. ${ }^{2}$ Some papers use the expected school starting age, defined by the birth date in relation to the school entry cut-off dates, as an instrument for the actual school starting age to examine the effect of school starting ages on test scores, completed year of schooling, and later labor market outcomes (e.g. Black et al., 2011; Fredriksson and Öckert, forthcoming). Relatedly, since a seminal paper by Angrist and Krueger (1991), many studies in the US combine this with the compulsory school law to instrument for years of schooling.

However the underlying assumption for these instruments to be valid is that the births at different quarters or neighborhood of school entry cut-off dates are indeed random. In fact, parents who plan to have children face a clear trade-off to time a birth either before or after the school entry cut-off dates. The key feature is that many countries require children to reach a certain age by a specified date in the calendar year in order to start primary school, and therefore those who are born a day apart from the cut-off date enter the school at different age. The benefit of shifting birth before the school entry cut-off date is that parents can send their children to school at a relatively young age, and thus avoid a year of child care costs, and lost wages from reduced labor force participation in order to care for their children. ${ }^{3}$ The benefit of shifting birth after the school entry cut-off date is that older children within an academic cohort is shown to peform better in school (e.g. Bedard and Dhuey, 2006). ${ }^{4}$

Whether parents react to the incentives, and if so which incentive dominates is an empirical question. I use universe of birth certificate records 1974-2010 in Japan which reports exact date of births to assess whether parents systematically time childbirth before or after this eligibility cut-off date.

There are two key institutional features that make Japan an interesting setting where the timing of birth is very important for parents. First, the delay of the entry into primary school is very rare in Japan. In fact, Kawaguchi (2012) documents that only 0.03 percent of primary

\footnotetext{
${ }^{2}$ See e.g., Bedard and Dhuey, 2006, 2012; Berlinski et al., 2011; Black et al., 2008, 2011; Cascio and Schanzenbach, 2007; Crawford et al., 2007; Datar, 2006; Dhuey and Lipscomb, 2010; Dobkin and Ferreira, 2010; Elder and Lubotsky, 2009; Fertig and Kluve, 2005; Fredriksson and Öckert, forthcoming; Leuven et al., 2010; McCrary and Royer, 2011; McEwan and Shapiro, 2008; Muhlenweg and Puhani, 2010; Puhani and Weber, 2007; Stipek, 2002; Strom, 2004.

3 There is some convincing evidence that availability of kindergarten affects mother's labor supply (e.g., Berlinski and Galiani, 2007; Cascio, 2009; Gelbach, 2002; Schlosser, 2011). These findings suggest that kindergarten or schools implicitly serve as a child care center.

${ }^{4}$ The evidence come from a cross-country study by Bedard and Dhuey (2006) and country-level studies by Kawaguchi (2011) for Japan, Elder and Lubotsky (2009) for the United States, Fredriksson and Öckert (forthcoming) for Sweden, Puhani and Weber (2007) for Germany, Strom (2004) for Norway, Crawford et al. (2007) for England, and McEwan and Shapiro (2008) for Chile. Researchers try to understand if the cause of this academic disadvantage for younger children is either due to absolute age at which they start the school or relative age to the peers (e.g. Datar, 2006; Elder and Lubotsky, 2009).
} 
school age children are exempted from the mandatory starting age in Japan. ${ }^{5}$ Therefore the timing of births indeed decides when the children start primary schools later. This setting is in contrast to the case in the US where significant fraction of children defer school entry by a year, making them the oldest students (Deming and Dynarski, 2008). Second, there is only one single school entry cut-off date that applies to all children in Japan. This is also in contrast to the case in the US; since each state has different school entry cut-off dates, and inter-state migration is pretty common, parents may not know precisely which school entry cut-off date that they should refer to. ${ }^{6}$

I find that more than 1,800 births per year are shifted roughly a week before the school entry cut-off date to a week following the cut-off date. Since I observe a gradual decline and a subsequent gradual increase in the number of births around the cut-off date, this shift of births is more consistent with real shift instead of fraud or misreporting. Also I observe that the birth weight of children born after the cut-off date is slightly heavier, and the probability of overweight (>4000 grams) is also slightly higher, strengthening the claim that the timing of births is real instead of pure manipulation. This finding of delaying births suggests that on average the parents care more about children's academic performance than additional cost of child care at least in Japanese setting.

The overall shifts in births, however, masks heterogeneous responses of mothers. Non-working mothers are more likely to delay births, which is consistent with the notion that opportunity cost of non-working mothers is smaller than those of working mothers. Interestingly among those working, mothers with low skilled jobs are more likely to shift births before the school entry cut-off dates. This result implies that for some mothers financial burden of child care outweighs the importance of future academic advantage of children. Also male births are much more likely to be delayed than female births. These findings consistently point to one direction: births around the school entry cut-off dates reflect the differences in mother's socioeconomic status as well as mother's preferences, and thus may not be random.

Finally, I also examine the health outcomes measured as infant mortality. If the surge in the number of births right after the school entry cut-off date creates the congestion or overcrowding in hospitals, it could potentially harm the health of infants. On the other hand, it may not affect the infant health since hospitals can anticipate such a surge, and thus they are well prepared. Consistent with the latter view, I do not find that births born right after the school entry cut-off date reveal the excess infant mortality.

This paper is related to several strands of literature. First, this paper contributes to a small

\footnotetext{
${ }^{5}$ Note, however, that this is not only unique to Japan. Bedard and Dhuey (2006) lists four countries for which there is little or no evidence of early/late starting or grade retention: England, Iceland, Japan, and Norway.

${ }^{6}$ For example, school entry cut-off date for California is December 1, and that for Texas is September 1. For school entry cut-off dates in each state in the US, see Dickert-Conlin and Elder (2010). For international school entry cut-off dates, see Bedard and Dhuey (2006). Note that most countries only have single school entry cut-off date unlike the case of the US.
} 
but growing literature which examines the impact of the incentives created by birth-related cut-off dates on the timing of births. Since the use of birth-related cut-offs to determine eligibility for policy programs is quite common across the world, past studies have analyzed the timing of births in very different settings and institutions that rely on cut-off dates that were known to parents before delivery. ${ }^{7}$ This paper is unique from previous studies in two ways; while other papers investigate the short-term financial incentives created by birth-related cut-off dates such as tax benefits or monetary bonuses, this paper examine the incentives that affect the long-term outcomes of children; also while other studies examine the incentives that goes only one direction (either delays or hastening), this paper analyze the case where there is clear trade-off in incentive structure.

Second, this result provides evidence on the power that parents exert on the timing of births. While there is ample evidence that a certain number of births can be indeed timed, it is generally not clear whether this timing is due to doctors/hospitals or parents. For instance, using my data from birth certificates I observe that the number of births that occurs on weekends or holidays is lower by around 25 percent than on weekdays. Since doctors/hospitals certainly prefer not to have congestions, this surge in the number of births right after the school entry cut-off dates suggests that parents have some power vis- a-vis doctors/hospitals on the timing of the deliveries.

Third, most importantly this paper is related to the literature that exploits the identification strategy that assumes that births around the school entry cut-off dates are random. ${ }^{8}$ Notably, the recent paper by Buckles and Hungerman (forthcoming) shows that winter births are disproportionally realized by teenagers and the unmarried in the US. But no paper has showed that birth around the school entry cut-off dates is not random. In fact, there are a few papers which examined this question: Dickert-Conlin and Elder (2010) in the US, McCrary and Royer (2010) in Texas and California in the US, McEwan and Shapiro (2008) in Chile, and Berlinski et al. (2011) in Argentine. This is the first paper that documents the solid evidence that school entry cut-off date affects the timing of births.

The remainder of this paper is organized as follows. Section 2 provides background information on the school system. Section 3 describes the data used herein, and the identification strategy. Section 4 reports the main results and section 5 discusses the implications of the findings. Section 6 concludes.

\footnotetext{
${ }^{7}$ Some papers find the evidence on shift in the timing of births, while others do not. For example, shifts of birth timings are found in tax incentives in the US (Dickert-Conlin and Chandra, 1999; Maghakian and Schulkind, 2012; LaLumia et al., 2013); tax incentives in Japan (Kurenishi and Wakabayashi, 2008); bonus payment in Australia (Gans and Leigh, 2009); parental leave benefit reform in Germany (Tamm, 2012, Neugart and Ohlsson, 2013); while shifts are not found in expansion of job-protection leave in Germany (Dustmann and Schonberg, 2012); extending the leave duration in Austria (Lalive and Zweimuller, 2009).

${ }^{8}$ For the instruments to be valid, instruments have to satisfy two conditions: exclusion restrictions and relevance. Most of past literature questions the relevance, i.e., weak instrument, such as Bound et al. (1995). Here the issue is about exclusion restrictions.
} 


\section{Background}

\subsection{School System}

In this sub-section, I briefly describe the school system in Japan. The school entry cut-off dates in Japan has been set April 2 since 1947, and it has not changed since then. The school system in Japan is legally defined in the School Education Law (SEL) enacted in 1947. SEL article 22 mandates parents to send their children to primary schools as soon as their children turn age six before the school starting day, which is April 1 in Japan. However, according to Japanese law, people reach the additional age a day before their birthday. This means that actual school entry cut-off date is April 2 instead of April 1; children born on April 1 enter primary schools on their 6th birthday, while those born on April 2 enter primary schools on a day before their 7 th birthday. So there is about a 1-year age difference at the maximum among primary school students in the first grade.

This rule is strictly enforced in Japan and thus students rarely delay or start primary school earlier than scheduled date. Indeed, SEL Article 23 allows a delay in school entry due to a child's illness or underdevelopment, but this exception is rarely applied. According to Kawaguchi (2010), the percentage of exemption is 0.03 percent. ${ }^{9}$ This is not surprising as parents had to formally apply for an exception together with the proof of underdevelopment/illness from the doctors specified by the local educational advisory board (SEL article 34).

The fact that almost all children start attending school without delay contrasts with the situation in the US, where postponing kindergarten or school attendance (or referred to "redshirting") has become popular among educated parents (Datar, 2006; Elder and Lubotsky, 2009; Cascio and Schanzenbach, 2007; Dobkin and Ferreira, 2010). Also Japanese educational system is known for social promotion system, where automatic promotion occurs from one grade to the next. The SEL Article 23 also does not prohibit students from learning in the grade above the scheduled grade, but the advancement is also very rare.

Also compulsory schooling in Japan is not defined by the age when students can leave, but by the length of the years; 9 years of education ( 6 years in primary school and 3 years in junior high school) is uniformly required for all children. Therefore there is no systematic variation in years of schooling based on the timing of births unlike the US (Angrist and Kruger, 1991). This means parent in Japan do not face a well-known tradeoff in schooling in the US where though students who are the youngest in their school cohort typically have poorer academic performance, on average, they have slightly higher educational attainment (Dobkin and Ferreira, 2010).

\footnotetext{
${ }_{9}$ In 2004, 7,200,933 children at the primary school age (ages 6-12) attended primary schools, while 2261 did not according to Kagaguchi (2010).
} 


\subsection{Birth Registration}

The birth certificate is written by the physicians if birthd occur at the either hospitals or clinics, while it is written by midwives in case of deliveries at home. Hospitals are those with more than 20 beds, and clinics are those with less than 20 beds or no bed in Japan. According to the birth data described in detail below, 99.4 percent of births occur at medical institutions (either at hospitals or clinics) during 1974-2010.

Then the parents are required to bring the birth certificates to register the birth at the near-by public health center (hokenjyo). Therefore if the fraud of reported birth date happens, it may be more likely to happen at the delivery stage at medical institutions or home rather than reporting stage at the public health center. The births need to be registered within 14 days after births; otherwise parents need to pay a fine.

\section{Data and Identification Strategy}

\subsection{Data}

The primary data for this analysis are the universe of birth record that covers all births occurred in Japan during 1974-2010 compiled by Ministry of Health, Labour and Welfare. The key variable in the birth data is the exact date of births. Combining 1974-2010 birth data together provides me with information on over 50 million births. The data are of high quality in that only 4,935 observations (less than $0.01 \%$ ) are missing birth dates information, and I drop these observations. The birth data also contains information on exact hour of births, which is rare in the public-version of birth certificates available to the researchers. Otherwise specified, the main interest of outcome is the mean daily number of births instead of hourly births since most of the literature uses the daily observations, and thus comparable across studies.

The birth data also reports limited mother's characteristics such as ages. Unfortunately, they do not collect education of mothers, delivery method (such as C-section and inducement), complications of births, and Apgar scores. Given this limitation, I examine the heterogeneous responses by mothers' observable characteristics available in the dataset. However, fortunately, for every five years, the birth certificates collect information on working status of mothers at the time of delivery (not at the time of conception), and roughly 10 categories of mother's job types for working mothers. I divide the 10 categories of job types into high skilled jobs, medium skilled jobs and low skilled jobs. Appendix Table A summarizes the occupational categories. These measures are used to examine the heterogeneous responses by mother's job types, which may be a proxy to the income.

I also examine the child characteristics collected in the birth certificates to investigate whether the shifts in the timing of births are indeed real shift in the timing instead of pure manipulation by looking at the birth weight of children as well as gestational length of 
mothers. I also examine a gender of child, and a parity of child.

In addition to birth certificates, I use the death certificates to examine the infant mortality. The death certificates contain a unique record of each death occurring in the Japan, which includes information about the decedent's exact date of death, exact date of birth, gender, and cause of death (ICD8-10). While the birth and death certificates are not linked in Japan, I count the number of deaths for births born each birth date from death certificates (the numerator) and the number of births for each birth date from birth certificates (the denominator), and calculate the infant mortality rate on each birth date. Summary statistics is reported in Appendix Table B.

\subsection{Identification Strategy}

Let birth $_{d y}$ be counts of births for day $d$ in year $y$. Days are organized in relation to the April 2 for each year. Given this structure for the data, the econometric model I estimate is:

$$
\begin{gathered}
\text { birth }_{d y}=\alpha+\beta \text { After }_{d y}+\sum_{j=1}^{6} D O W(j)_{d y} \gamma_{j}+\sum_{k=1}^{N} \operatorname{Holiday}(k)_{d y} \delta_{k}+\theta_{y}+\varepsilon_{d y} \\
\ln \left(\text { birth }_{d y}\right)=\alpha+\beta \text { After }_{d y}+\sum_{j=1}^{6} D O W(j)_{d y} \gamma_{j}+\sum_{k=1}^{N} \operatorname{Holiday}(k)_{d y} \delta_{k}+\theta_{y}+\varepsilon_{d y}
\end{gathered}
$$

where $A f t e r_{d y}$ takes one if the birthday $d$ is after April 2 in each year $y . D O W(j)$ is one of six dummy variables for the different weekdays, and Holiday $(k)$ of $K$ dummy variables for holidays throughout the year. The coefficient of interest is $\beta$. The variable $\theta_{y}$ captures year effects, and $\varepsilon_{d y}$ is an idiosyncratic error term. The year indicators are included to account for time trends in the overall number of births. ${ }^{10}$ Using the log number of births in equation (2) provides a measure of the proportion of births shifted.

I change the windows around the April 2, from 7 days to 28 days following Gans and Leigh (2008). Widening the window has two purposes. First, it allows for births to have been moved by more than one week even though as I show later, birth shifting is concentrated within a week from the cut-off date. Second, it allows for the possibility of "attempted but unsuccessful moves", where some parents may have attempted to delay their births until April 2, but instead only could move the birth date from mid-March to late-March. Also, if capacity constraints are binding, some births that would have taken place in the early-April may be shifted to mid-April. Both of such moves attenuate the estimates from focusing on a narrow window.

I also examine the child characteristics around the school entry cut-off date. Here I use the individual birth as a unit of observation instead of counts at each birth date. The equation I

\footnotetext{
${ }^{10}$ I also tried to include day of week*year fixed effect to allow each week day to have differential impact by each year. The results are very similar.
} 
estimate is:

$$
\mathrm{Y}_{i d y}=\alpha+\beta \text { After }_{i d y}+\sum_{j=1}^{6} D O W(j)_{i d y} \gamma_{j}+\sum_{k=1}^{N} \operatorname{Holiday}(k)_{i d y} \delta_{k}+\theta_{y}+\varepsilon_{i d y}
$$

for each outcome $Y$ for individual birth $i$ born in year $y$, and day $d$. To account for common characteristics within the same birth date, the standard errors are clustered at the birth date.

\section{Results}

\subsection{Shift in the Timing of Births}

Before running formal statistical analysis, the simple histogram of mean daily number of births reveals the striking pattern. Figure 1 reports the mean daily number of births throughout the year using the pooled 1974-2010 birth data. The markers with cross sign correspond to the holidays. Note once again that school entry cut-off date is April 2 instead of April 1. To my knowledge, nothing other than school entry cut-off dates lies on this specific day. ${ }^{11}$

Figure 1 displays that there is clearly a heaping on April 2, and relatively high frequency of births on subsequent days. In fact, April 2 is the day with the highest number of births throughout the year, and April 1, a day before the cut-off date, is the third lowest. Table 1 reports the top 5 and bottom 5 days of the year in terms of mean daily number of births, together with the relative number of births, computed as the average births on a given day divided by the average birth across all days. Thus, a value of 1.1 represents a 10 percent increase in the daily births compared to the average in the year. April 2, and April 3 see 20 and 10 percent more births than average, while April 1, a day before the cut-off date, sees 15 percent less births than average. This graph also shows the importance of controlling for holidays in the estimation. There is also variation in the weekdays vs. weekends, but pooling many years of data takes out such an effect in the figure. In the regression, I include the day of the week fixed effects to control for the within week fluctuations.

A closer look at births around the cut-off date is provided in Figure 2 that plots the mean daily number of births around April 2 using pooled 1974-2010 birth data. To provide symmetry, I report the 28 days prior to the April 2 (March 4 -April 1), and the 28 days after April 2 (April 2-April 29). Again, the markers with cross sign correspond to the holidays. Figure 2A simply displays the mean daily number of births. Starting about 10 days before April 2, daily number of births gradually declines, and falls to roughly 2,800 per day on April 1, a day before the school entry cut-off date. The number of births then sharply increases to roughly 4,500 on April 2. The difference between a day before and after the school entry cut-off date is as much as 1700 births with an average of 3,713 births per day throughout the

\footnotetext{
11 For example, tax year is January 1 to December 31 in Japan. See Kurenishi and Wakabayashi (2008) on
} taxes and timing of births in Japan. 
year. Note that other dips around March 20 and April 29 are the result of holiday: Spring Equinox Day (either March 20 or 21), and Greenery day (April 29), respectively. Figure 2B accounts for weekend, and holidays by plotting the residual of regressions of the daily number of births on weekday and holiday fixed effects. This graph shows the similar pattern as Figure $2 \mathrm{~A}$.

Table 2 summarizes the results from formal statistical test of estimating equation (1) and (2). First column in Panel A restricts the sample to the last 7 days and first 7 days around April 2 , and it shows that roughly 1,835 births are shifted within 7 days from April 2. In the remaining columns, I progressively widen the window of analysis. As I widen the window, the number of births shifted does not change much, suggesting that most of the shift in the timing of births is concentrated within the first and last 7 days from the school entry cut-off date. Panel B use natural log of the mean daily birth as an outcome. The first column shows that roughly 7.0 percent of births are shifted from a week before April 2 to a week after.

Some of the birth shift can be potentially due to the manipulation of reported birth date. However, since I observe the gradual decline of births roughly from 10 days prior to April 2, it seems unlikely that manipulation of reported birth date can account for all the birth shifts. Also as mentioned earlier the shifts cannot be driven by the home deliveries where manipulation seems easier since 99.4 percent of births occur either at medical institutions during 1974-2010. ${ }^{12}$ Further evidence against pure manipulation story is shown later when I examine the birth weight of infants, and gestational length of mothers.

A unique feature of the birth certificates in Japan is that they also report exact hour of birth in addition to exact date of births. Figure 3 plots hourly number of births within 72 hours (3 days) before and after the school entry cut-off dates using the pooled 1974-2010 birth data. The graph shows systematic patterns within a day, where more births are observed during the daytime and fewer births on late at night and early in the morning. Interestingly, I observe bunching of reported births on the midnight of April 2nd, and a slight dip just a few hours before the midnight. I do not observe such a pattern around the midnights of other days. While it may reflect the manipulation of the reported birth hours, since delaying births a few hours is much easier than delaying births for a few days, it is also consistent with the real shift of births.

In both analysis using the exact date of births, and exact hour of births, I find that mothers shift births in response to the school entry cut-off dates. Note that this result may underestimate the change in the timing of births, since mothers can in addition time the conceptions instead of births to make sure that children are born after the school entry cut-off dates. I will come back to this point later in Section 5.

\footnotetext{
12 The fraction of births at home is in the declining trend, but even in 1974, the first year of the data available, the fraction of home deliveries is only $1.07 \%$. It is $0.18 \%$ in 2010 , the last year available.
} 


\subsection{Heterogeneous Responses by Mothers' and Child Characteristics}

Exploiting the characteristics of mother and children, I aim at shedding a light on the incentives by parents behind the shift of the timing of births. Figure 4-7 plots the mean daily number of births by a parity of child, mother's age, mother's working status, mother's job types, and gender of child. Table 3 summarizes the results from estimating equation (2) where outcome is log of the mean daily number of births separately for each sub-group. Since the shifts of births are concentrated within a week, I estimate equation within 7 days from the cut-off date from here. Appendix Table C and D presents results from different size of windows.

Figure 4A display that births at higher parity is more likely to fall behind the school entry cut-off date. This pattern is more apparent in Figure 4B which plots the share of high parity birth ( $2^{\text {nd }}$ and above) among all births. ${ }^{13}$ The figure shows that share of high parity births increases right after April 2. Panel $\mathrm{C}$ in Table 3 reports while 8.6 percent of birth at high parity is delayed within 7 day window, which for $1^{\text {st }}$ birth is 5.3 percent. The null hypothesis that coefficients on different parties are the same is rejected at 1 percent level. This result implies that mothers may learn from the previous experience of first child that it is probably beneficial for forthcoming children to fall behind the school entry cut-off date to make sure that children are older within the grade. Also mothers have more experience at the higher parity of births, and thus easier to time births than first child.

Figure 5A displays that relatively younger mothers less than 30 years old show a larger delay of births, compared to mothers more than 30 years old. ${ }^{14}$ Because of this differential pattern by mother's age group, Figure 5B displays a decline in mean mother's age at birth right after the school entry cut-off date. One possible explanation is that for older mothers it is much more important to make sure that they are going to have a kid and thus care less about the timing the births. Also since the delay of births can be potentially harmful to the mother's health, the delays of births for older mothers may be physically difficult, and doctors/hospital may not agree on the mother's request to delay births.

Next, I examine the differential responses by mothers' working status and mothers' type of jobs among working mothers. Since the opportunity cost of working mothers is higher than that of non-working mothers, working mothers may be less likely to delay the births. To examine this prediction, I divide the sample into working and non-working mothers. Note that mother's working status is only collected every five years ending with last digit of 0 and 5, and thus sample size in this analysis is smaller.

\footnotetext{
${ }^{13}$ The fraction of $2^{\text {nd }}$ or above births among all births seems to be increasing after April 2 in the graph. Appendix Figure A shows that $2^{\text {nd }}$ births are more observed in spring after April 2, while $1^{\text {st }}$ births are more observed in summer/fall. It is possible that parents become more aware of the importance of the timing of births at the second births or simply are more comfortable to give births in spring than summer or winter. In any case, this figure is consistent with the fact that some of the mothers carefully time the conception in the US (Buckles and Hungerman, forthcoming).

${ }^{14}$ Note that mean age of birth is 29.81 years old.
} 
Figure 6A clearly shows that non-working mothers are more likely to delay the timing of births than working mothers. Panel $\mathrm{C}$ in Table 3 reports that while non-working mothers shifts 11.3 percent of births within 7 days of school entry cut-off date, the corresponding number is only 3.5 percent for working mothers. The coefficients on working and non-working mothers are statistically different at 1 percent level.

However, the results for working mothers may mask the heterogeneous responses by the mothers with different types of job. Figure 6B displays the mean daily number of birth by mothers' job type among those working. Interestingly, mothers with low skilled jobs are more likely to shift births before the school entry cut-off dates. This result implies that while the opportunity cost is smaller for those mothers with low skilled jobs than those of high or medium skill jobs, financial burden of child cares forces mothers to time births earlier than school entry cut-off dates to avoid the additional year of child care cost. In fact, Panel D in Table 3 reports that while roughly 20 percent of births are shifted backward among mothers with high and medium skilled jobs, the mothers with low skilled jobs (and hence arguably low income) shifts birth forward by roughly 18 percent of births within 7 days of school entry cut-off date.

The arguably most interesting results are the mother's differential responses by the gender of births. Figure 7A clearly reports that male births are more likely to be delayed than female births. Figure 7B plots the fraction of male births, and the figure shows that the share of male birth is substantially higher after the school entry cut-off date. Panel $\mathrm{E}$ in Table 3 reports while 8.0 percent of male births are delayed within 7 day window, 6.1 percent of female births are delayed. ${ }^{15}$ I can reject the null that coefficients on male and female births are the same at the conventional level. Appendix Table D presents results of estimation for gender by parity within different size of windows around the cut-off date. Consistent with the finding so far, Appendix Table D shows that male births at higher parity are most likely to be delayed.

There are a couple of possible explanations for this finding. First, this may reflect the son preference of the parents. If so, it is interesting since Japan is known to reveal little son preference in the prenatal stage, and therefore shows normal sex ratio at births unlike many of Asian countries with elevated sex ratio at births (Sen, 1990, 1992). This result may imply a different form of son preference at postnatal stage instead of prenatal stage such as sex-selective abortion. Second, this differential gender responses by parents may reflect the fact that boys are slower in the development in the early childhood and also socially less mature than girls so that parents want to make sure that male births do not suffer from disadvantage of being the youngest within the school grade in the future. ${ }^{16}$ Unfortunately, I

\footnotetext{
15 Instead, I simply regress male birth dummy as an outcome in equation (3). The coefficient on After is 0.009 (SE 0.001), and statistically significant at 1 percent level.

${ }^{16}$ For example, Datar (2006) shows that boys benefit significantly more in reading from delaying entrance to kindergarten compared to girls.
} 
cannot disentangle each story.

Overall, the findings here consistently point to one direction: births around the school entry cut-off dates reflect the differences in mother's socioeconomic status as well as mother's preferences, and thus may not be random. This can be shown from the fact that parity of child, mother's age, mother's working status, mother's job types, and gender of child are all discontinuous around the school entry cut-off dates.

\subsection{Child Outcomes}

Since I observe the gradual decline before April 2, it seems unlikely that manipulation of reported birth date accounts for the entire shift in the timing of births. Here I show further evidence against pure manipulation by examining the birth weight of children, and gestational length of mothers. Birth weight is of particular importance as there is ample evidence that initial health at birth has consequences for medium and long-term outcomes of children (e.g. Black et al., 2007; Oreopoulos et al., 2008; Royer, 2009; Johnson and Schoeni, 2011; Bharadwaj et al., 2012). I am aware of only three previous papers by Gans and Leigh (2009) and Tamm (2012), and Maghakian and Schulkind (2013) that analyze the impact of cut-off induced birth timing on infant health.

Figure 8A plots the mean birth weight around April 2. ${ }^{17}$ The graph clearly shows that births after the school entry cut-off dates are heavier than those before April 2. Figure 8B plots the probability of births more than 4,000 grams, and shows similar patterns as mean birth weight. Table 4 presents the results of estimating equation (3) using the individual birth as a unit of observation. Column (1) in Table 4 reports that birth weight is roughly 2.3 gram heavier for those born after school entry cut-off date. Since 7.0 percent of births are shifted backward, this would imply that births that are actually delayed are heavier by around 33 grams. ${ }^{18}$ This result is also consistent with the fact that boys tend to be heavier than girls at the time of deliveries. ${ }^{19}$ Column (2) reports that birth after school entry cut-off date is 0.05 percentage point more likely to be over 4000 grams (mean of 2.2 percent). I also find that probability of births delivered after more than 42 weeks of gestation is higher after April 2 in Column (3), which is consistent with the increase in birth weight. ${ }^{20}$

After having shown that there were sizeable shifts in births, I finally analyze health of

\footnotetext{
17 The birth weight is collected with 100 grams interval till 1995, and therefore I stick with this measure and divide the birth weight collected in grams after 1995 by 100 .

18 Appendix Table E presents results from different size of windows around the cut-off date.

19 If increase in the birth weight is concentrated in the recent years, it raises the concern that some of the shifts in the early period are due to the manipulation of reporting instead of real shifts. However, increase in birth weight can be clearly observed in the early periods as well (not shown).

${ }^{20}$ I am also currently collecting the health insurance claim data which reports the delivery method of births. Planned C-sections and inducement of births may increase after the school entry cut-off date. This is the same data used for Shigeoka and Fushimi (2012) that examines the NICU utilization in Japan except that both data covers different period.
} 
infants measured by the infant mortality. One the one hand, if the surge in the number of births right after the school entry cut-off date creates the congestion or overcrowding in hospitals, it could potentially harm the health of infants. On the other hand, it may not affect the infant health since hospitals can anticipate such a surge, and thus they are well prepared. Consistent with the latter view, Figure 8D shows that while the mortality profile is noisy due to the low mortality rate in Japan, there is no clear change in infant mortality. Column (4) in Table 4 confirms that births born right after the school entry cut-off date do not show the excess mortality. ${ }^{21}$

\subsection{Availability of Public Day-care Centers}

The differential responses by mothers' working status and mothers' type of jobs among working mothers in the preceding sub-sections is consistent with the opportunity cost story. In this sub-section, I further explore whether the easier access to child cares, and hence the lower cost of raising child, affects the timing of the births. The idea behind is that the more available the day-care is at the region, the more I may observe the delays of births, since additional year of child care is less worrisome for mothers in these regions. I am certainly aware that this is simply a correlation and not causal estimates since there is no explicitly exogenous regional variation on public day-care centers availability. Nonetheless this is a relevant and interesting correlation and therefore this exercise should be viewed as a complement to the analysis in the preceding section.

As a measure of availability of child care, I exploit the year-to-year regional variation of availability of public day-care centers. More specifically, I compute the "capacity" measure by dividing the total slots of public day-care centers by the total number of females between ages $20-39$, the child-bearing age. ${ }^{22}$ This measure captures the "potential" availability of child care instead of the "actual" availability of child car, where the total slots of the public day-care centers is often divided by the number of children before school entry age instead of the number of females in childbearing age as I do here. This measure is arguably better than actual day-care availability, since the number of children is the result of mother's fertility decisions, and hence potentially endogenous to the timing of births shifts (Unayama, 2012). There is considerable regional variations in capacity variable - ranging from 0.0355 (Kanagawa, 1974) to 0.293 (Ishikawa, 1979) with mean of 0.144 (SD 0.053) slot per females.

I estimate the effect of the availability of public day-care centers on the magnitude of the birth shifts in the following two steps. First, I estimate the following equation (4) for each prefecture $p$ and each birth year $y$ cell separately using 7 days window from the cut-off:

\footnotetext{
${ }^{21}$ Since I am interested in the effect of birth complications due to congestion on infant mortality, I also restricted infant deaths in the sample to those that occurred within 28 days of birth (neonatal death), and in which the death is classified as being caused by 'conditions originating in the perinatal period' (specifically, ICD-10 category P). The results are similar (not shown).

22 The number of female population is interoperated through the Census which is collected every five years in the year ending with 0 or 5 .
} 


$$
\ln \left(\operatorname{birth}_{d}^{y p}\right)=\alpha^{y p}+\beta^{y p} A f t e r_{d}^{y p}+\sum_{j=1}^{6} D O W(j)_{d}^{y p} \gamma_{d}^{y p}+\sum_{k=1}^{N} \operatorname{Holiday}(k)_{d}^{y p} \delta_{d}^{y p}+\varepsilon_{d}^{y p}
$$

This equation is simply the analogue to the equation (2), but $\beta^{y p}$ is estimated at each prefecture/year-of-birth cell instead of using all pooled data at once, thus generating a series of estimate across prefecture/year-of-birth. ${ }^{23}$ Note that since the equation is estimated for each year, I no longer include the year of birth fixed effects. ${ }^{24}$ There are 47 prefectures in Japan.

In the second step, I estimate the following equation (5) where I regress this magnitude of delays at prefecture/year-of-birth cell, $\hat{\beta}^{y p}$, on a capacity measures as I mentioned above.

$$
\hat{\beta}^{y p}=\alpha+\beta \ln \left(\text { capacity }_{(y-1) p}\right)+\gamma_{p}+\theta_{y}+\delta X_{y p}+\mu_{y p}
$$

Note here that since capacity variable is collected as of October 1 in each year, I use the capacity variable in $y-1$, a year prior to March/April when the shifts of births occur in year $y$. $X_{y p}$ is time-varying prefecture chacateristics, and I specially include the real GDP per capita which is deflated by prefecture GDP deflator to Yen in 2000, and job application-to-opening ratio at October of $y-1$, which roughly captures prefecture labor market conditions around the time of conception to control for selection into fertility. In fact, Dehejia and Lleras-Muney (2004) highlighted the effect of the business cycle on the average characteristics of mothers who conceived children in the US. I also include application-to-opening ratio in March of the year $y$, to account for the economic condition at the time of births as well. ${ }^{25}$ These controls essentially have no impacts on the estimates. The source of variable and years available are summarized in Appendix Table F.

Table 5 summarizes the results from estimating equation (5). Column (1) reports that the 10 percent increase in the capacity of public day-care centers increases the magnitude of the delays by 1.4 percent. This result is consistent with the view that better access to public day-care centers reduces the cost of child care, and hence mothers are more willing to delay the births. While it cannot be interpreted as causal, it may imply that increase in the availability of public day-care may exacerbate the shifts of the births.

Adding time-varying controls in Column (2) does not virtually affect the estimate. In Column (3), I run the same equation as (5) but here I use the mean daily number of births at each prefecture/year-of-birth as weights. While the estimates are slightly smaller, it still remains highly statistically significant at the conventional level. Finally, to check whether my results are driven by prefectures with large populations which tend to have low availability of

\footnotetext{
${ }^{23}$ Note that this is conceptually the same as pooling the data for all years of births, and including all the interaction of independent variables with a full set of prefecture/year-of-birth dummies.

${ }^{24} \hat{\beta}^{y p}$ vary from -0.127 to 0.387 with mean of 0.082 and standard deviation of 0.063 .

25 While more standard measure of labor market conditions such as unemployment at the prefecture level is only available in the census years, the monthly job application-to-opening ratio at the prefecture level is available since as early as 1963 in Japan.
} 
public day-care centers, Column (4) excludes Tokyo and Osaka, two biggest prefectures. The result is essentially the same as Column (3).

In sum, I find that the results are consistent with the hypothesis that cost of the child care may be the one driving force of shifts in the timing of births. However, I need to view this result with a caution since the availability to public day-care is just a proxy of the cost of child care. ${ }^{26}$ Also again, I stress that I can only provide correlations and not causal estimates here.

\subsection{Patterns of Shifts across Period}

In this sub-section, I explore the patterns of shifts across period. Appendix Figure B displays the mean daily number of birth around April 2 by different time periods. While the magnitude of the shifts is largest in the earliest period (1974-1980), I also see the discernible delays of births in the most recent decade (2001-2010).

To gauge the magnitude, Appendix Figure $\mathrm{C}$ plots the size of the shifts in each year, which is estimated by running the regression equation (2) separately for each year with 7 days window from the cutoff. Note that since the equation is estimated for each year, I do not include the year fixed effect in the estimation.

There are two things worthwhile to mention. First, across all years, the estimates on the shifts are all positive and statistically significant at the conventional level, indicating that the timing of the shifts is not limited to a certain period. For example, the proportion of births shifted is 5.2 percent in 2010 (7.0 percent during entire 1974-2010), the last available year in the dataset.

Second, I observe that magnitude of the delays of births is declining in the recent years. One may expect to observe more delays of births in the recent years due to the development of medical technology to easily time births as well as more familiarity of the mothers with information on academic advantage of older children. ${ }^{27}$ However, on the other hand, if I consider the characteristics of mother who recently give births, i.e., more first parity, more by working mothers, and more by older mothers, all these factors point to the opposite direction (i.e. less delays in the births). Also the digitalization of the medical record may make it harder to manipulate the birth date in the recent years.

It is clear that the change in the composition of mothers can not driving the entire results of decline in the shifts since Appendix Figure D shows that even within the groups such as mother's working status, and mother's type of jobs, the patterns and magnitude of the shifts are changing across period. For example, Panel B in the figure displays that the forwarding instead of delaying the timing of births among mothers with low skilled jobs became more

\footnotetext{
${ }^{26}$ While there are private day-care centers, public day-care centers tent to be cheaper than private day-care centers.

${ }^{27}$ For example, the fraction of weekend births has been increasing from 16 percent in 1974 to 36 percent in 2010, which may reflect that fact that births can be more easily timed through elective C-section and inducement as medical technology advances.
} 
apparent in late 1990s, and it gets accelerated in the most recent year of 2005.

Nonetheless, to examine how much of the recent decline in the magnitude of the shifts can be explained by the change in the composition of the mothers, as well as to investigate the key characteristics of mothers that mostly affect the difference in the magnitude of delays, I perform a simple exercise as below to decompose the magnitude of the shifts into the component explained by the compositional change of mothers, and that of remaining.

To simplify, I consider a case where there are two time period $t(t=0$ and 1$)$, and two group $\mathrm{g}(\mathrm{g}=\mathrm{A}$ or $\mathrm{B})$. For example, $\mathrm{t}$ is zero in year 1975 and $\mathrm{t}$ is one in 2010, and two groups are younger mothers less than 30 year old $(\mathrm{g}=\mathrm{A})$ and mothers above 30 year old $(\mathrm{g}=\mathrm{B})$.

Let $\beta_{t}$ as the coefficients from equation (2) estimated separately for each period $\mathrm{t}$, and then $\beta_{t}$ can be written as

$$
\beta_{t}=W_{t}^{A} \beta_{t}^{A}+W_{t}^{B} \beta_{t}^{B}
$$

where $W_{t}^{g}$ ( $\mathrm{g}=\mathrm{A}$ or $\mathrm{B}$ ) is the fraction of mothers in each group (which sums up to 1 ) in period $\mathrm{t}$, and $\beta_{t}^{g}(\mathrm{~g}=\mathrm{A}$ or $\mathrm{B})$ is coefficients from equation (2) estimated separately for each group in period t. Both $W_{t}^{g}$ and $\beta_{t}^{g}$ are calculated or estimated using the observations within 7 days from the cut-off dates.

The goal here is to understand what fraction of the differences between $\beta_{0}$ and $\beta_{1}$ can be explained by the change in the composition of mothers across period (i.e., $W_{0}^{g}$ and $W_{1}^{g}$ ). To do so, I simply follow Blinder-Oaxaca decomposition. More specifically,

$$
\begin{aligned}
& \beta_{1}-\beta_{0} \\
= & \left(W_{1}^{A} \beta_{1}^{A}+W_{1}^{B} \beta_{1}^{B}\right)-\left(W_{0}^{A} \beta_{0}^{A}+W_{0}^{B} \beta_{0}^{B}\right) \\
= & \left(W_{1}^{A} \beta_{1}^{A}+W_{1}^{B} \beta_{1}^{B}\right)-\left(W_{0}^{A} \beta_{1}^{A}+W_{0}^{B} \beta_{1}^{B}\right)+\left(W_{0}^{A} \beta_{1}^{A}+W_{0}^{B} \beta_{1}^{B}\right)-\left(W_{0}^{A} \beta_{0}^{A}+W_{0}^{B} \beta_{0}^{B}\right) \\
= & {\left[\left(W_{1}^{A}-W_{0}^{A}\right)^{*} \beta_{1}^{A}+\left(W_{1}^{B}-W_{0}^{B}\right)^{*} \beta_{1}^{B}\right]+\left[W_{0}^{A}\left(\beta_{1}^{A}-\beta_{0}^{A}\right)+W_{0}^{B}\left(\beta_{1}^{B}-\beta_{0}^{B}\right)\right] } \\
= & {\left[\Delta W^{A} \beta_{1}^{A}+\Delta W^{B} \beta_{1}^{B}\right]+\left[W_{0}^{A} \Delta \beta^{A}+W_{0}^{B} \Delta \beta^{B}\right] } \\
= & {[\text { explained by compositional change }]+[\text { unexplained }] }
\end{aligned}
$$

The groups I consider here are: mothers' age group (below vs. above 30 years old), parity $\left(1^{\text {st }}\right.$ vs. $2^{\text {nd }}$ or above), gender of child (boys vs. girls), working status (non-working vs. non-working), and type of jobs among working mothers (low vs. high skilled jobs). I choose 1975, first year when mother's working status is collected, as the base year $(t=0)$. The results of this exercise are summarized in Appendix Table G. ${ }^{28}$

For example, between $1975(\mathrm{t}=0)$ and $2005(\mathrm{t}=1)$, and mothers' age group (A is less than 30 years old, while $\mathrm{B}$ is more than 30 years old), the decomposition can be done as follows:

$$
-0.165
$$

\footnotetext{
28 Instead I could have done the Blinder-Oaxaca decomposition at multi-dimensions instead of one dimension. The issue with the mutli-dimension approach is that further I divide the sample (say mother's age group/working status cell), the estimates become less precise due to the smaller sample (results are available from the authors).
} 


$$
\begin{aligned}
& =0.069-0.234 \\
& =\beta_{1}-\beta_{0} \\
& =\left[\left(W_{1}^{A}-W_{0}^{A}\right)^{*} \beta_{1}^{A}+\left(W_{1}^{B}-W_{0}^{B}\right)^{*} \beta_{1}^{B}\right]+\left[W_{0}^{A}\left(\beta_{1}^{A}-\beta_{0}^{A}\right)+W_{0}^{B}\left(\beta_{1}^{B}-\beta_{0}^{B}\right)\right] \\
& =[\text { explained }]+[\text { unexplained }] \\
& =[-0.022]+[-0.143]
\end{aligned}
$$

Thus 13 percent $(0.022 / 0.165)$ of the difference in coefficients between 1975 and 2005 can be explained by the change in the mothers' age composition between two periods, and the rest of 87 percent remains as unexplained by mother's age group.

Appendix Table G shows that except for year 2005, the change in mothers' age may explain the decline in the magnitude of the delays most. However, mother' age can only account for 5-20 percent of the change in the magnitude except for 48 percent in year 1980. Parity and gender of births explains little since the distribution of these two factors is pretty stable throughout the years.

Notably, the pattern is quite different in 2005; increase in the fraction of working mothers in 2005 account for the all decline in delays between 1975 and 2005, and among those working mothers the change in the type of jobs account for 37 percent of the decline in the magnitude of delays. The drastic change in the patterns in 2005 can be attributed to the revision of the labor law that expanded the type of jobs that are allowed for firms to hire temporary workers. ${ }^{29}$ As seen from Appendix Table G, fraction of working mother substantially increases from 2000 to 2005 (17 percentage points), so as the fraction of mothers with low skilled jobs among working mother (25 percentage points). As shown in section 4.2, the change of these two mother's characteristics is consistent with the reduction of the delays in the timing of births.

Overall, the changes in the parental characteristics I examined across period do not appear to explain most of the declines in the delays of births except for 2005. The other factors such as the increase in the difficulty of manipulating the reported birth date in recent years may be the other potential explanation.

\section{Discussion}

\subsection{Magnitude of the shifts}

Here I examine the magnitude of the shifts by comparing this study to the previous studies that also look at the effect of birth-related cut-off on the timing of births in other context. The results are summarized in Table 6 . Three things are noteworthy to mention. First, the school entry cut-off dates are known well in advance like tax benefits so that the timing of both conceptions as well as births could be potentially affected by the school entry cut-off

29 "Order for Enforcement of the Act for Securing the Proper Operation of Worker Dispatching Undertakings and Improved Working Conditions for Dispatched Workers" are revised in Dec 1, 1999 and March 3, 2004. 
dates unlike the case of bonus payment which only affect the timing of births. Second the incentives created by the school entry cut-off date affect the later outcome of children, while other studies examine the immediate financial incentives such as bonus payment. Third, while incentive structure in the other studies go in one direction (i.e., either delays or hastening of births), there is a clear tradeoff for school entry cut-off dates examined here. Despite these differences, 7 percent shifts of births found in this study is within the range of other studies.

\subsection{Randomness of births}

The findings in this paper have implication for the growing literature that relies on the identification strategy that assumes that births around the school entry cut-off dates are random. Most papers use the expected school starting age (defined by the birth month or days in relation to the school entry cut-off dates) as an instrument for the actual school starting age to examine the effect of school starting ages on test scores, completed years of schooling, and later labor market outcomes (e.g., Black et al., 2011, Fredriksson and Öckert, forthcoming). Relatedly, a seminal paper by Angrist and Krueger (1991) showed that individuals born in the 1st quarter of the year have lower education attainment than those born in the 4th quarter of the previous year in the US. Such difference in educational attainment was arguably due to the interaction of compulsory schooling laws with school entry laws, which makes individuals born in the 1st quarter more likely to start school later and therefore more likely to quit formal education once they reach a certain age specified in the compulsory schooling laws. Recent papers use more precise information on the exact date of births instead of quarter of birth, and use the day of birth in relation to the school entry date to instrument for years of schooling (e.g., McCrary and Royer, 2011).

However, the validity of such instruments depends on the assumption that birth timing is random. In fact, recent studies question the validity of such assumption. Notably, the recent paper by Buckles and Hungerman (forthcoming) shows that winter births are disproportionally realized by teenagers and the unmarried in the US. ${ }^{30}$ But no paper has showed that birth around the school entry cut-off dates is not random.

As for studies using Japanese school entry cut-off date, Bedard and Dhuey (2006) exploit the school entry cut-off date among OECD countries, which does include Japan, and show that younger children within the academic cohort do perform worse than older children. Kawaguchi (2010) also finds that those born in March have worse test scores, less completed year of schooling and lower wages than those born in April. Both papers use the month of births instead of day of birth, which could partially mitigate the concerns of sample selection by averaging out the characteristics of children and mothers. However, as shown in the Figure 9, even at the monthly level, mothers who give birth in March are potentially negatively

\footnotetext{
${ }^{30}$ See also Bound and Jaeger (2000), Dobkin and Ferreira (2010), Cascio and Lewis (2006), Barreca et al. (2011), and Carlsson et al. (2012) on nonrandomness of birthdate.
} 
selected compared to those who give birth in April: they tend to be more likely to be working but with low skilled jobs. Therefore their finding of academic disadvantage among younger children may be partially driven by the selection of mothers. ${ }^{31}$ Put differently, the disadvantage of March born children to April born children can be the combination of "double negative" effects; younger within the school cohort, and born by mothers with low socioeconomics status. Ideally I would like to know how much of the disadvantage is steming from the selection of mothers and from being younger within the school cohort. Unfortunately, Trends in International Mathematics and Science Study (TIMSS) data for Japan, used by both Bedard and Dhuey (2006) and Kawaguchi (2010), do not collect any of the key socioeconomic status of mothers such as educational attainment. Therefore I cannot test whether their findings are attenuated once controlling for mother's socioeconomics characteristics. ${ }^{32}$

\section{Conclusion}

Parents are known to time birth in response to various incentives. Some papers have already documented that parents do react to incentives if the financial reward is immediate such as tax benefits and monetary bonuses but no paper has showed that parents also react to the less immediate incentives such as school entry cut-off date for children. Examining the universe of births in Japan, I find that mothers in Japan indeed shift the timing of birth in response to the school entry cut-off date. This result shows that mothers can be very forward looking, and thus time the births in response to the future outcomes.

The one remaining question is as to why I find the shifts of births in response to school entry cut-off date in Japan, while other studies in US, Chile and Argentine do not find such behavioral responses of mothers. The strict enforcement of school entry age in Japan, and social promotion education system without delays, and advancement, suggests that the stake of birth timing is much higher in Japan since it determines when the child start schools later in their life. Also having single school entry cut-off date makes it easier for parents to target the relevant date. Whether the shifts in the timing of births in response to the school entry cut-off date can be observed in other countries for which there is little or no evidence of early/late starting or grade retention as well as with single school entry cut-off date, namely, England, Iceland, and Norway, is the avenue for the future research.

${ }^{31}$ It is important to note that in addition to estimating each country separately, Bedard and Dhuey (2006) also pooled the data from countries with different school entry cut-off dates, and therefore include birth of month fixed effect to control for season of birth effects, and still find that older children perform significantly better than younger children within school-cohort.

32 While TIMSS in 1995 and 1999 indeed report the exact date of birth, the sample size of TIMSS at the daily level becomes extremely small (5-10 observation per day), and thus TIMSS is not suitable to examine the outcomes at the daily level. Also data used by Kawaguchi (2010) only collect up to the month of birth. Unfortunately, to my knowledge, I am not aware of any dataset in Japan which contains both the exact date of birth and the long term outcomes with modest sample size. 


\section{References}

Angrist, Joshua. D., and Alan B. Krueger. (1991). "Does compulsory school attendance affect schooling and earnings?” Quarterly Journal of Economics, 106(4): 979-1014.

Barreca, Alan, Melanie Guldi, Jason M. Lindo, and Glen R. Waddell. (2011) "Heaping-Induced Bias in Regression-Discontinuity Designs," NBER Working Paper No. 17408.

Bedard, Kelly, and Elizabeth Dhuey. (2006) "The Persistence of Early Childhood Maturity: International Evidence of Long-Run Age Effects," Quarterly Journal of Economics, 121(4): 1437-1472.

Bedard, Kelly, and Elizabeth Dhuey. (2012) "School-Entry Policies and Skill Accumulation Across Directly and Indirectly Affected Individuals," Journal of Human Resources, 47:643-68.

Berlinski, Samuel, and Sebastian Galiani. (2007) "The effect of a large expansion of pre-primary school facilities on preschool attendance and maternal employment," Labour Economics, 14(3): 665-680.

Berlinski, Samuel, Sebastian Galiani, and Patrick J. McEwan. (2011) "Preschool and maternal labor supply: Evidence from a regression discontinuity design," Economic Development and Cultural Change, 59(2): 313-344.

Bharadwaj, Prashant, Juan Eberhard and Christopher Neilson. (2012) "Do Initial Endowments Matter Only Initially? Birth Weight, Parental Investments and Academic Achievement in School," Mimeo.

Black, Sandra, Paul J. Devereux, and Kjell G. Salvanes. (2007) "From the cradle to the labor market? The effect of birth weight on adult outcomes," Quarterly Journal of Economics, 122: 409-439.

Black, Sandra, Paul J. Devereux, and Kjell G. Salvanes. (2011) "Too Young to Leave the Nest? The Effects of School Starting Age," Review of Economics and Statistics, 93(2): 455-467.

Bound, John, David A. Jaeger, and Regina Baker. (1995) "Problems with Instrumental Variables Estimation when the Correlation Between the Instruments and the Endogenous Explanatory Variables is Weak." Journal of the American Statistical Association, 90(430): 443-450.

Bound, John, and David A. Jaeger. (2000) "Do Compulsory School Attendance Laws Alone Explain the Association between Quarter of Birth and Earnings?," Research in Labor Economics, 19: 83 - 108 .

Buckles, Kasey and Daniel M. Hungerman. (forthcoming) "Season of Birth and Later Outcomes: Old Questions, New Answers," Review of Economics and Statistics.

Carlsson, Magnus, Gordon B. Dahl, Björn Öckert, and Dan-Olof Rooth. (2012) “The 
Effect of Schooling on Cognitive Skills," NBER Working Paper No. 18484.

Cascio, Elizabeth and Ethan Lewis. (2006) "Schooling and the Armed Forces Qualifying Test: Evidence from School-Entry Laws," Journal of Human Resources, 41(2): 294-318.

Cascio, Elizabeth. (2009) "Maternal labor supply and the introduction of kindergartens into American public schools," Journal of Human Resources, 44(1): 140-170.

Cascio, Elizabeth, and Diane W. Schanzenbach. (2007) "First in the Class? Age and the Education Production Function," NBER working paper No. 13663.

Crawford, Claire, Lorraine Dearden, and Costas Meghir. (2007). "When You Are Born Matters: The Impact of Date of Birth on Child Cognitive Outcomes in England," Institute for Fiscal Studies report.

Datar, Ashlesha. (2006) "Does Delaying Kindergarten Entry Give Children a Head Start?" Economics of Education Review, 15: 43-62.

Dehejia, Rajeev, and Adriana Lleras-Muney. (2004) 'Booms, Busts, and Babies' Health," Quarterly Journal of Economics, 119: 1091-1130.

Deming, David and Susan Dynarski. (2008) “The Lengthening of Childhood," Journal of Economic Perspectives, 22(3): 71-92.

Dhuey, Elizabeth and Stephen Lipscomb. (2010) "Disabled or Young? Relative Age and Special Education Diagnoses in Schools," Economics of Education Review, 29(5): $857-872$

Dickert-Conlin, Stacy and Amitabh Chandra. (1999) "Taxes and the Timing of Births," Journal of Political Economy, 107(1): 161-177.

Dickert-Conlin, Stacy and Todd Elder. (2010) "Suburban Legend: School Cutoff Dates and the Timing of Births," Economics of Education Review, 29(5): 826-841.

Dobkin, Carlos, and Fernando Ferreira. (2010) "Do School Entry Laws Affect Educational Attainment and Labor Market Outcomes?," Economics of Education Review, 29(1): 40-54.

Dustmann, Christian, and Uta Schönberg. (2012) "Expansions in Maternity Leave Coverage and Children's Long-Term Outcomes," American Economic Journal: Applied Economics, 4(3): 190-224.

Elder, Todd, and Darren Lubotsky. (2009) "Kindergarten Entry Age and Children's Achievement: impacts of state policies, family background, and peers," Journal of Human Resources, 44(3): 641-683.

Fredriksson, Peter, and Björn Öckert. (forthcoming) "Life-cycle Effects of Age at School Start," Economic Journal.

Fertig, Michael and Jochen Kluve. (2005) "The Effect of Age at School Entry on Educational Attainment in Germany," IZA discussion paper No. 1507.

Gans, Joshua S. and Andrew Leigh. (2009) "Born on the First of July: An (Un)natural 
Experiment in Birth Timing," Journal of Public Economics, 93(1-2): 246-263.

Gelbach, Jonah. (2002) "Public schooling for young children and maternal labor supply," American Economic Review, 92: 307-322

Imbens, Guido W., and Thomas Lemieux. (2008) "Regression discontinuity designs: A guide to practice," Journal of Econometrics, 142: 615-635.

Johnson, Rucker and Robert F. Schoeni. (2011) "The influence of early-life events on human capital, health status, and labor market outcomes over the life course," The B.E. Journal of Economic Analysis \& Policy (Advances), 11(3): 1-55.

Kawaguchi, Daiji. (2011) "Actual age at school entry, educational outcomes, and earnings," Journal of Japanese International Economies, 25(2): 64-80.

Kureishi, Wataru and Midori Wakabayashi. (2008) "Taxing the Stork," National Tax Journal, 61 (2): 167-187.

Lalive, Rafael and Josef Zweimüller. (2009) "How does parental leave affect fertility and return to work? Evidence from two natural experiments," Quarterly Journal of Economics, 124: 1363-1402.

LaLumia, Sarah, James M. Sallee and Nicholas Turner. (2012) "New Evidence on Taxes and the Timing of Birth," Mimeo.

Leuven, Edwin, Mikael, Lindahl, Hessel, Oosterbeek, and Dinand, Webbink. (2010). "Expanding schooling opportunities for 4-year-olds," Economics of Education Review, 29: 319-328.

Maghakian, Teny and Lisa Schulkind. (2011) "What a Difference a Day Makes: A New Look at Child Tax Benefits and the Timing of Births," Mimeo.

McCrary, Justin, and Heather Royer. (2011) "The Effect of Female Education on Fertility and Infant Health: Evidence from School Entry Policies Using Exact Date of Birth,” American Economic Review, 101(1): 158-195.

Muhlenweg, Andrea M. and Patrick A. Puhani. (2010) "The evolution of the school-entry age effect in a school tracking system," Journal of Human Resources, 45(2): 407-438.

McEwan, Patrick J., Joseph S. Shapiro. (2008) "The benefits of delayed primary school enrollment: Discontinuity estimates using exact birth dates," Journal of Human Resources, 43(1): 1-29.

Neugart, Michael, and Henry Ohlsson. (2013) "Economic incentives and the timing of births: evidence from the German parental benefit reform of 2007," Journal of Population Economics, 26: 87-108.

Oreopoulos, Phil, Mark Stabile, Randy Walld, and Leslie Roos. (2008) "Short-, medium-, and long-term consequences of poor infant health," Journal of Human Resources, 43(1): 88-138.

Puhani, Patrick A., and Andrea M. Weber. (2007) "Does the Early Bird Catch the 
Worm? Instrumental Variable Estimates of Educational Effects of Age at School Entry in Germany," Empirical Economics, 32: 359-386.

Royer, Heather. (2009) "'Separated by girth': US twin estimates of the effect of birth weight," American Economic: Journal Applied Economics, 1: 49-85.

Schlosser, Analía. (2011) "Public Preschool and the Labor Supply of Arab Mothers: Evidence from a Natural Experiment," Mimeo.

Sen, Amartya. (1990) More than 100 Million Women are Missing. New York Review of Books, 37(20): 61-66. http://ucatlas.ucsc.edu/gender/Sen100M.html

Sen, Amartya. (1992) “Missing Women,” British Medical Journal, 304: 587-88.

Shigeoka, Hitoshi and Kiyohide Fushimi. (2012) "Supply-Induced Demand in Newborn Treatment: Evidence from Japan,” Mimeo.

Stipek, Deborah. (2002) "At what age should children enter kindergarten? A question for policy makers and parents," Social Policy Report, 16(2): 3-16.

Strom, Bjarne. (2004) "Student Achievement and Birthday Effects," Norwegian University for Science and Technology working paper.

Tamm, Marcus. (2012) "The Impact of a Large Parental Leave Benefit Reform on the Timing of Birth around the Day of Implementation," Oxford Bulletin of Economics and Statistics, 1-17.

Unayama, Takashi. (2012) "The Possibility of Pursuing Both Marriage/Childbirth and Employment, and the Development of Nursery Schools," Japanese Economy, 39(1): 48-71. 
Figure 1: Mean daily number of births through the year

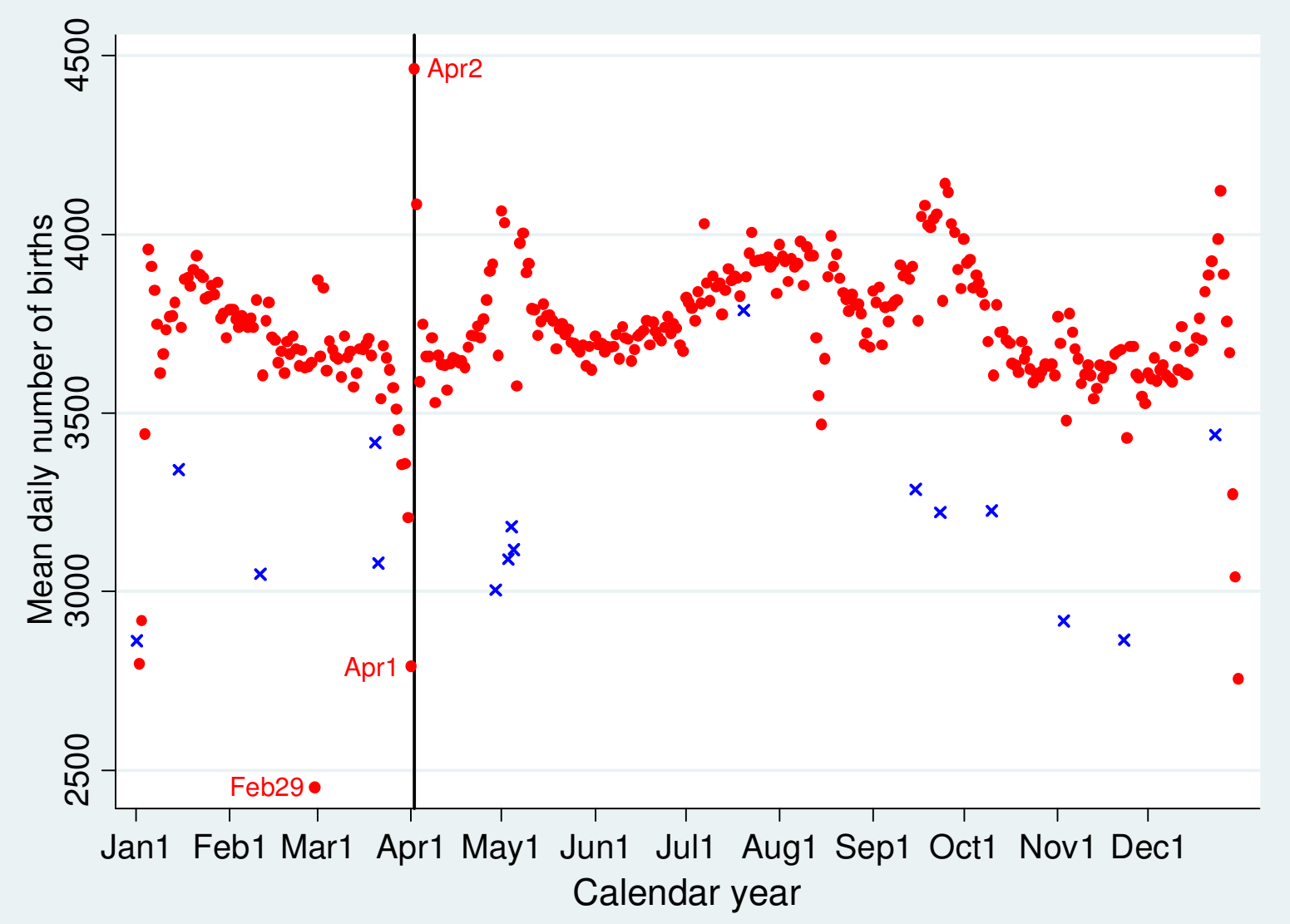

Note: The vertical line corresponds to April 2, which is the school entrance cut-off day in Japan. The data come from pooled 1974-2010 birth data. The markers with cross sign are holidays. 
Figure 2: Mean daily number of births around April 2

A. Raw

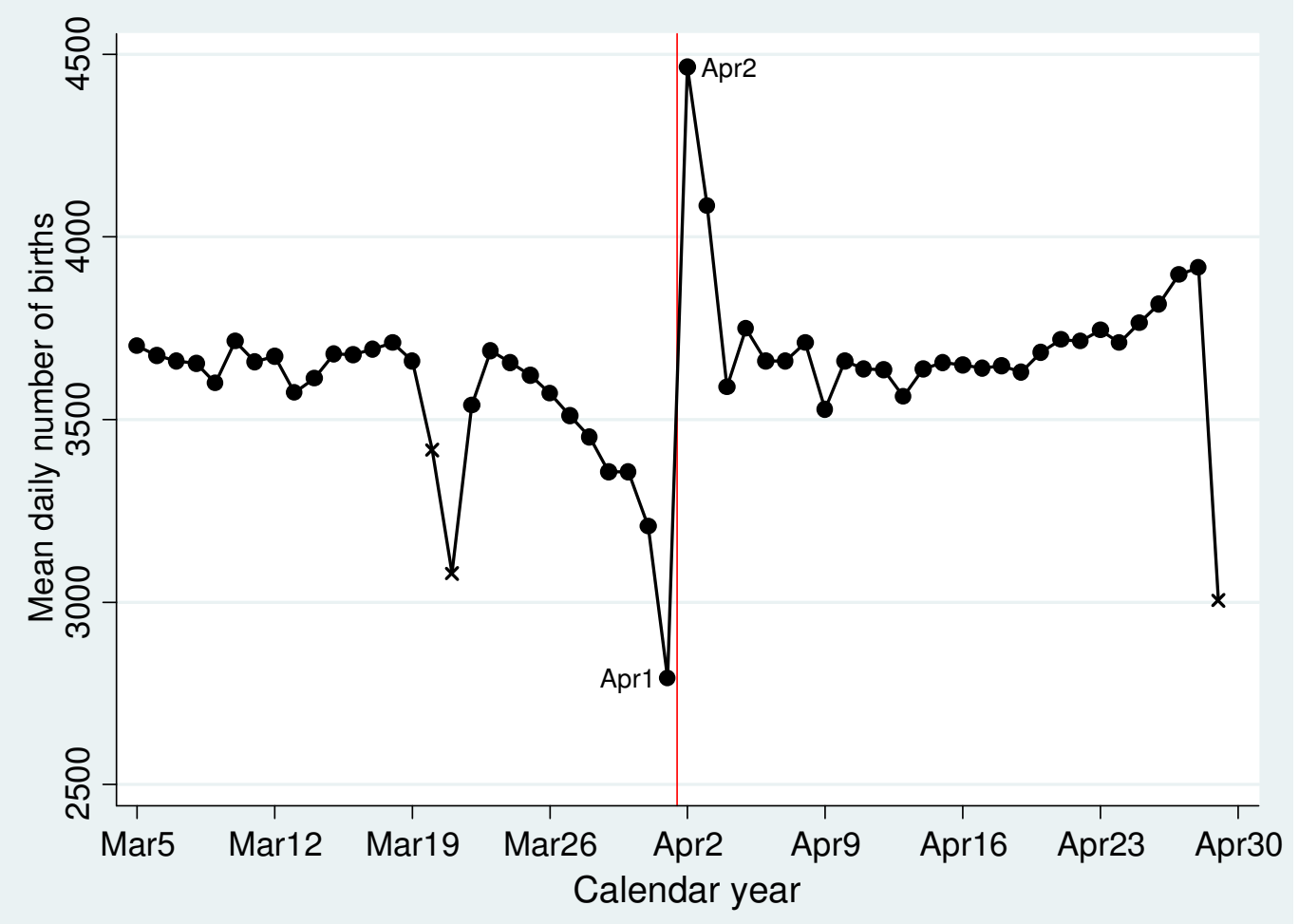

B. Adjusted

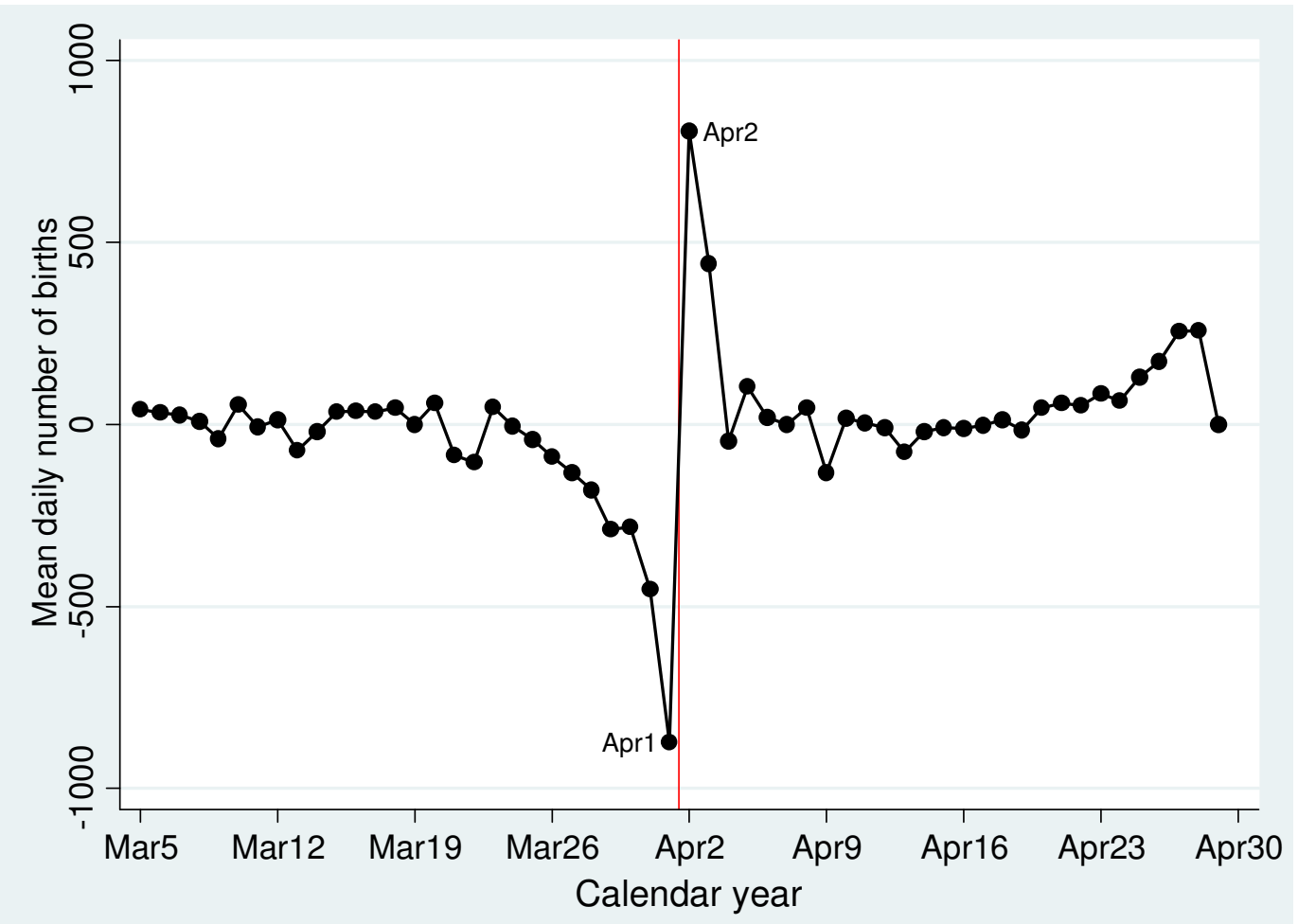

Note: The vertical line corresponds to April 2, which is the school entrance cut-off day in Japan. The data come from pooled 1974-2010 birth data. Each plot is the mean daily number of birth. The markers with cross sign in Panel A are holidays (either March 20 or March 21 depending on the year, and April 29). Panel B adjusts for holidays, year and day of week fixed effects. 
Figure 3: Reported birth hours within 72 hours from April 2

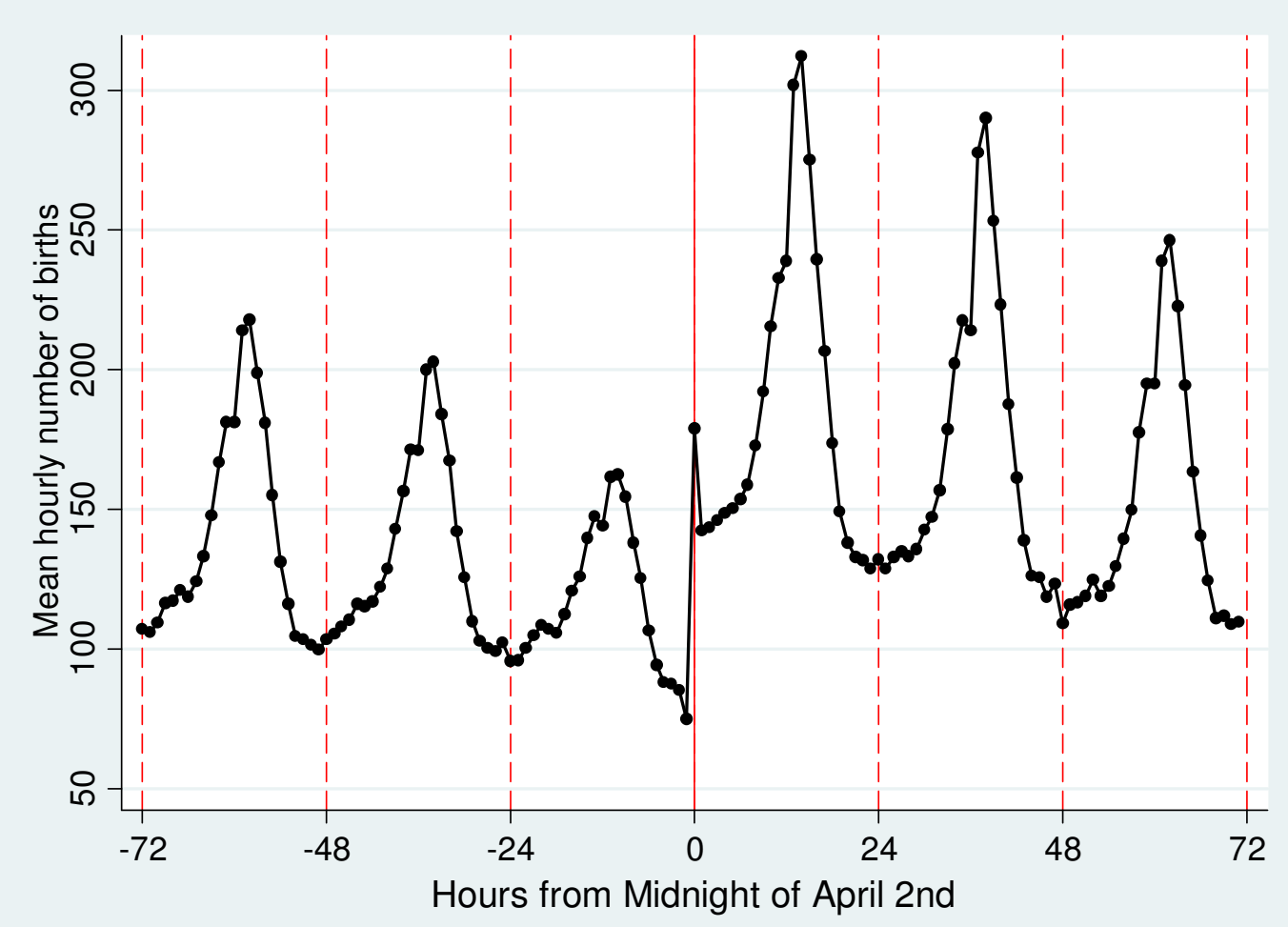

Note: The data come from 1974-2010 pooled birth data. The sold vertical line corresponds the midnight of Aprils 2, which is the exact school cut-off time in Japan. Every vertical dashed line corresponds to the midnight of other days. Each plot is the mean hourly number of births. 
Figure 4: Heterogeneous responses, by parity

A. Number of births by parity

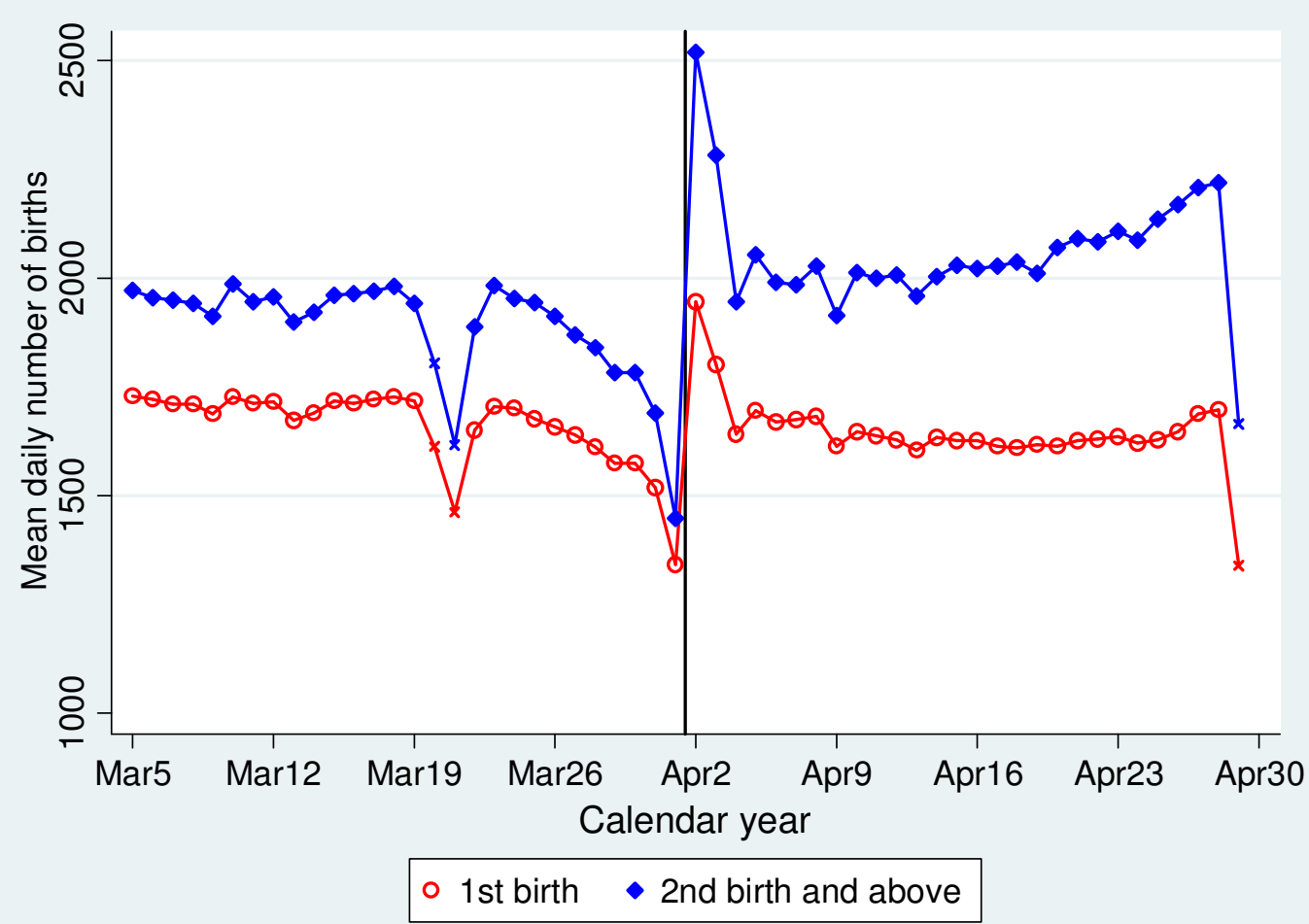

B. Fraction of $2^{\text {nd }}+$ births among all births

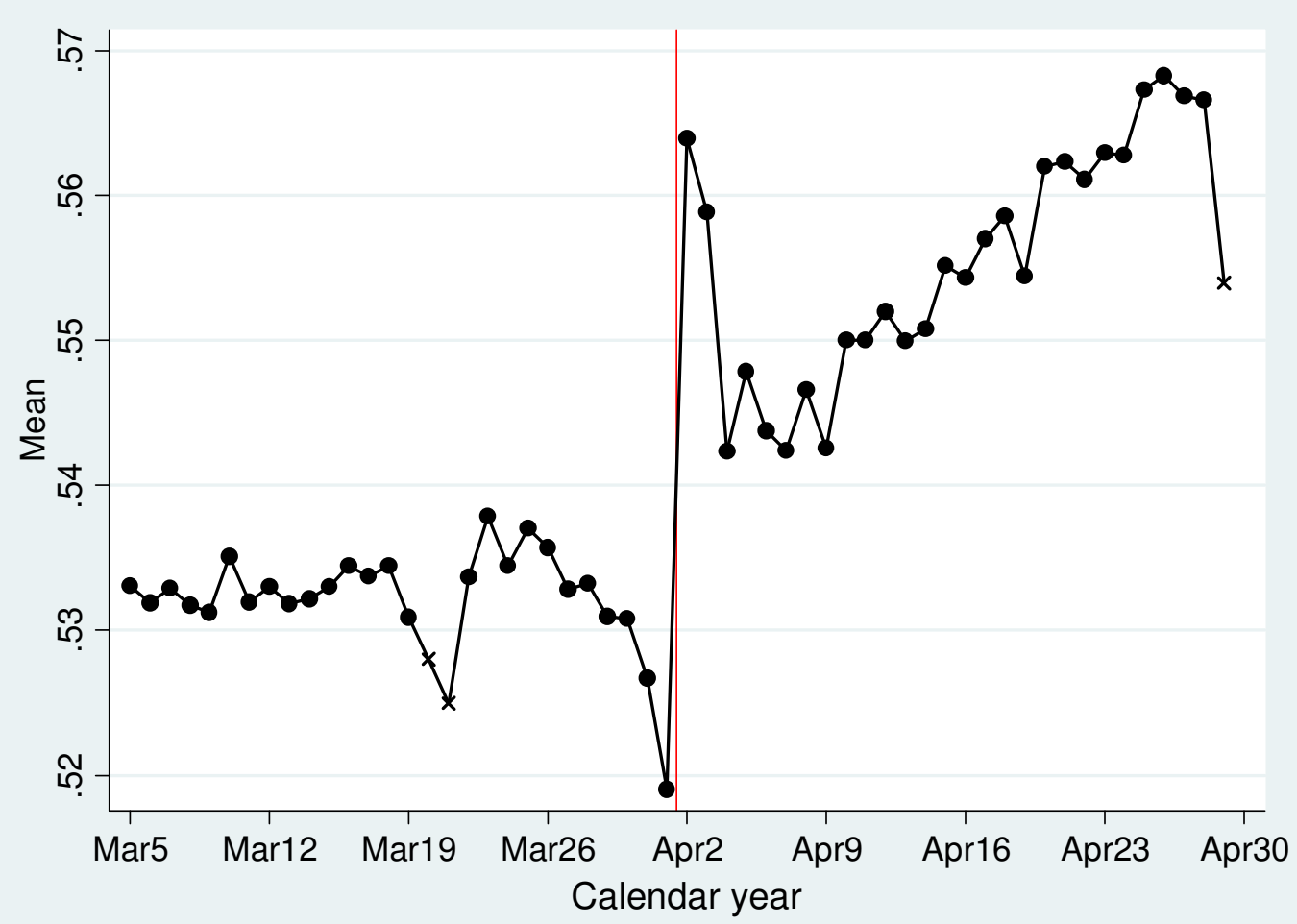

Note: The vertical line corresponds to April 2, which is the school entrance cut-off day in Japan. The data come from pooled 1974-2010 birth data. Each plot in Panel A is the number of births in each day. Each plot in Panel B is the mean of outcome in each day. The markers with cross sign in Panel A and B are holidays. 
Figure 5: Heterogeneous responses, by mother's age

A. Number of births by mother's age

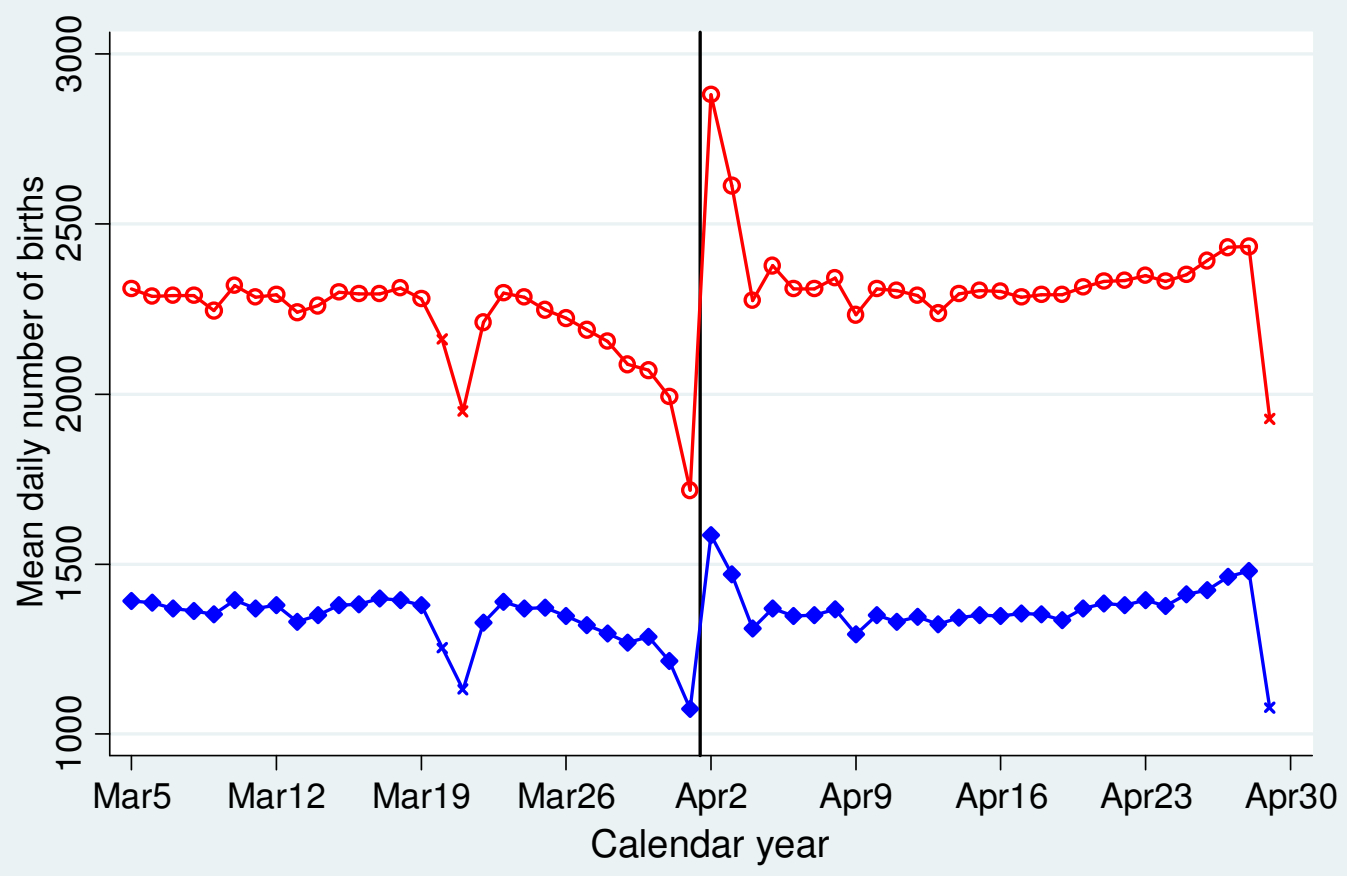

- Mother's age: below $30 \quad$ - Mother's age: above 30

B. Mother's age

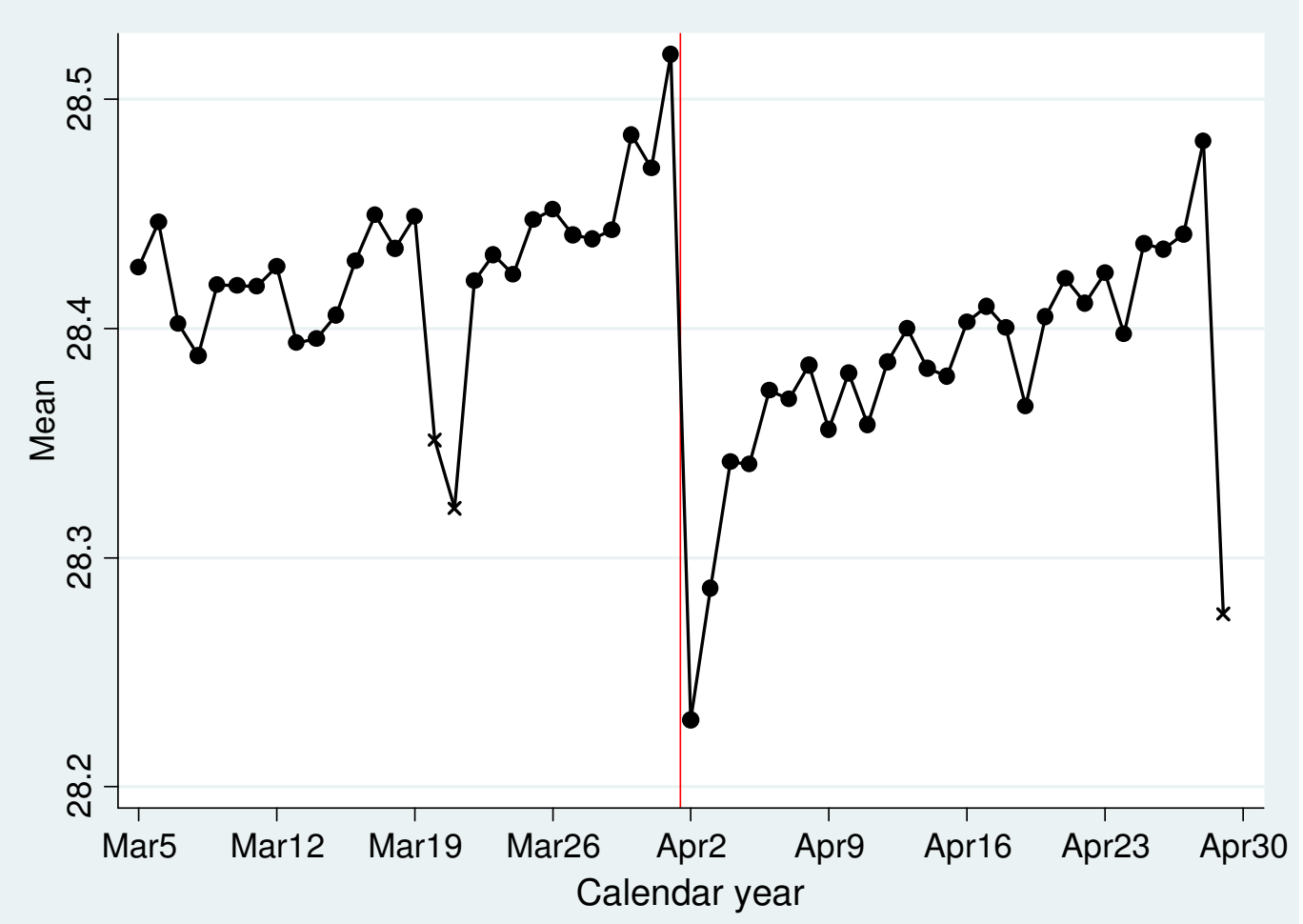

Note: The vertical line corresponds to April 2, which is the school entrance cut-off day in Japan. The data come from pooled 1974-2010 birth data. Each plot in Panel A is the number of births in each day. Each plot in Panel B is the mean of outcome in each day. The markers with cross sign in Panel A and B are holidays. 
Figure 6: Heterogeneous responses, by mother's working status

A. Working vs. non-working mothers

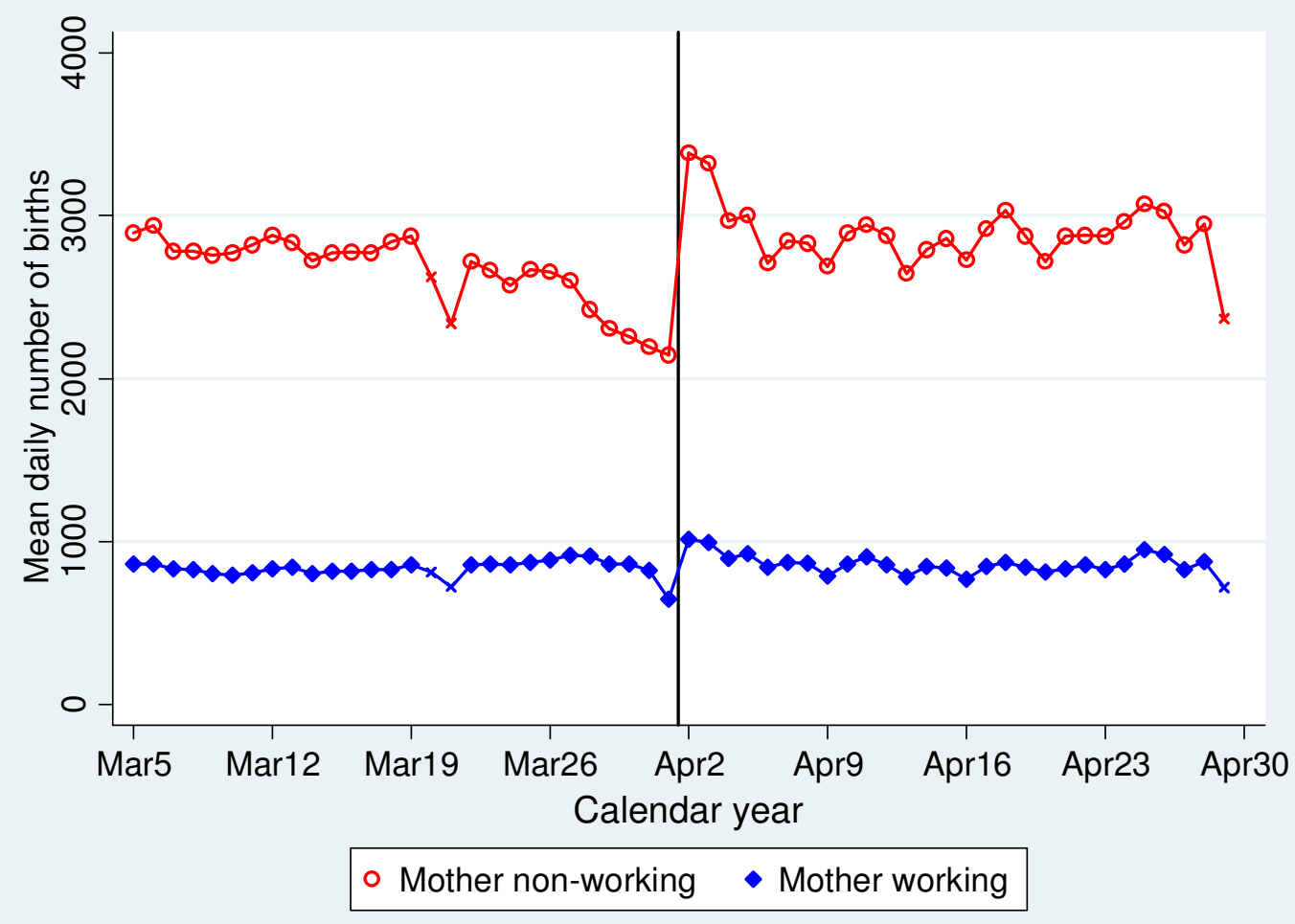

B. Among working mothers: Type of jobs

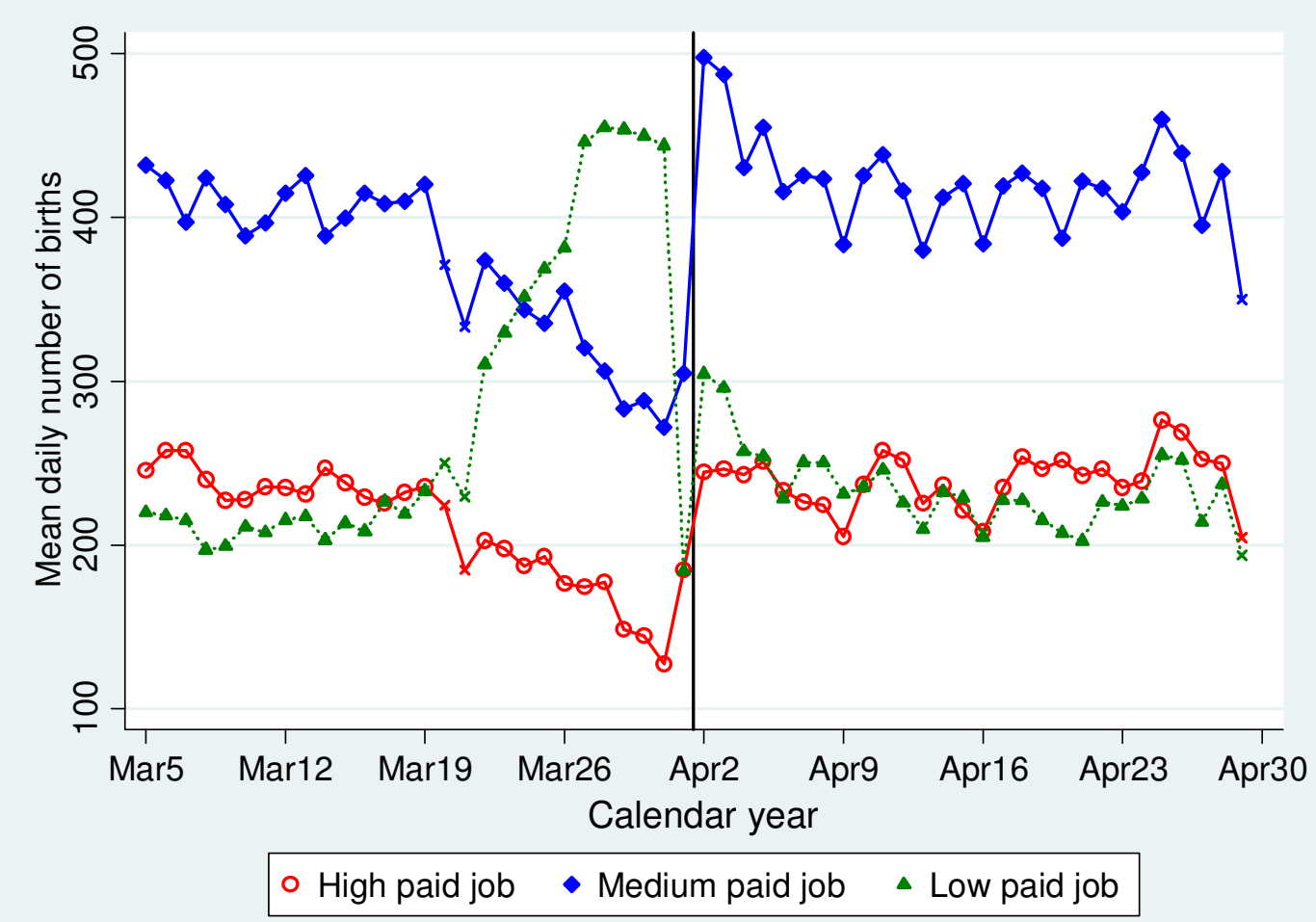

Note: The vertical line corresponds to April 2, which is the school entrance cut-off day in Japan. The data come from 1975, 1980, 1985, 1990, 1995, 2000, and 2005 pooled birth data. Each plot in Panel A is the number of births in each day. Each plot in Panel B is the mean of outcome in each day. The markers with cross sign in Panel A and B are holidays. 
Figure 7: Heterogeneous responses, by gender

A. Number of births by gender

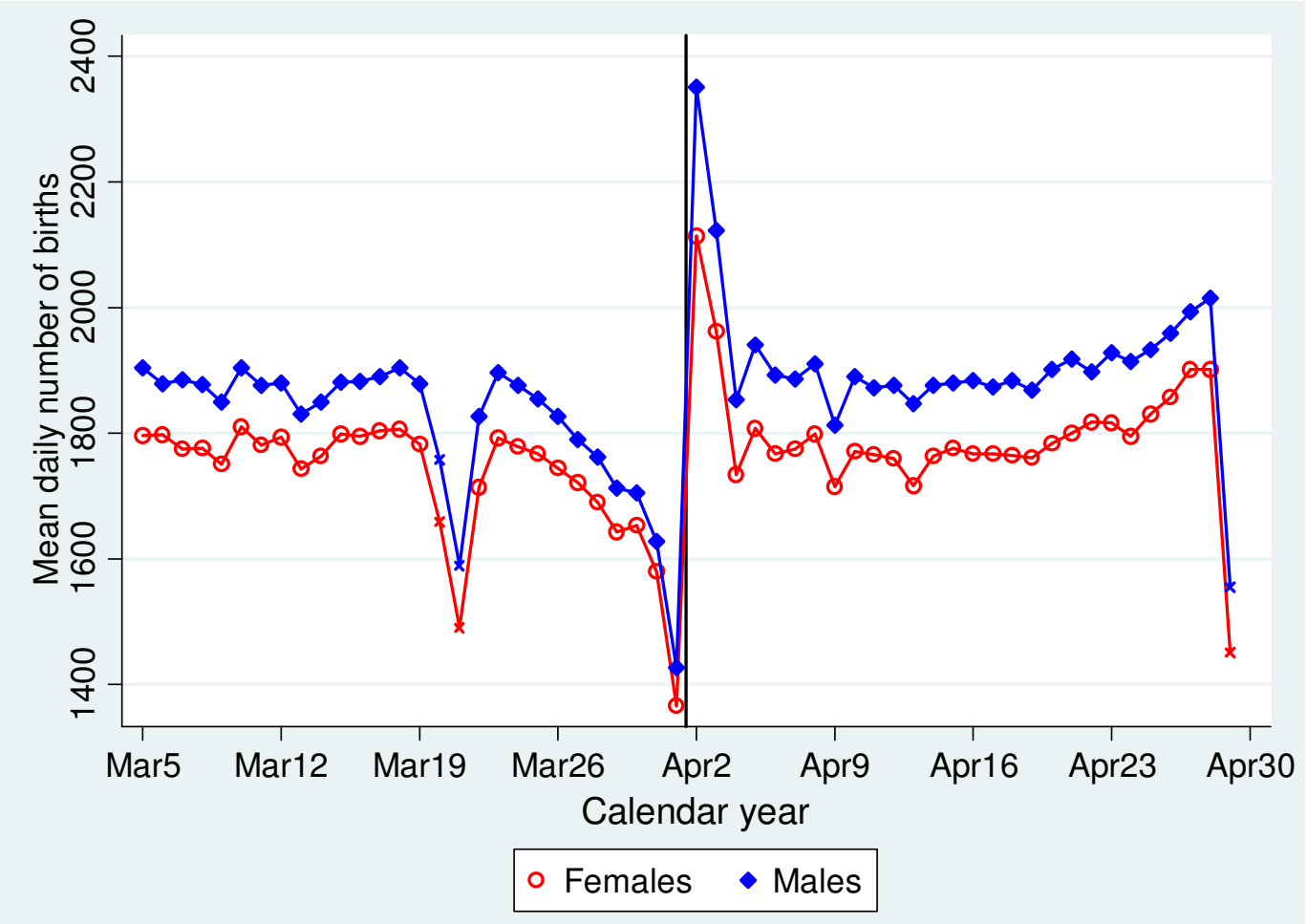

B. Fraction of male births

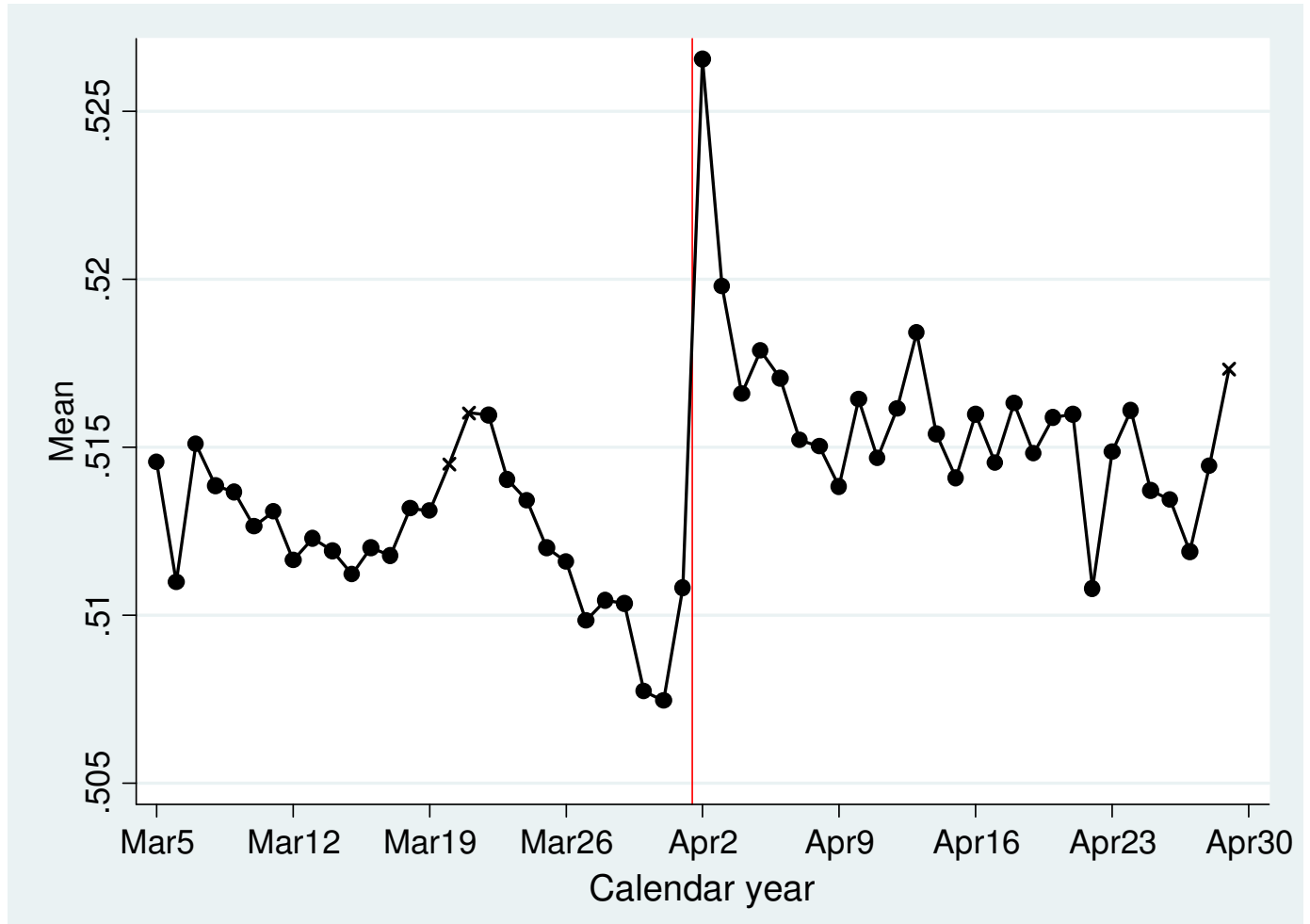

Note: The vertical line corresponds to April 2, which is the school entrance cut-off day in Japan. The data come from pooled 1974-2010 birth data. Each plot in Panel A is the number of births in each day. Each plot in Panel B is the mean of outcome in each day. The markers with cross sign in Panel 
A and B are holidays.

Figure 8: Child Outcomes

A. Mean Birth weight (100 grams)

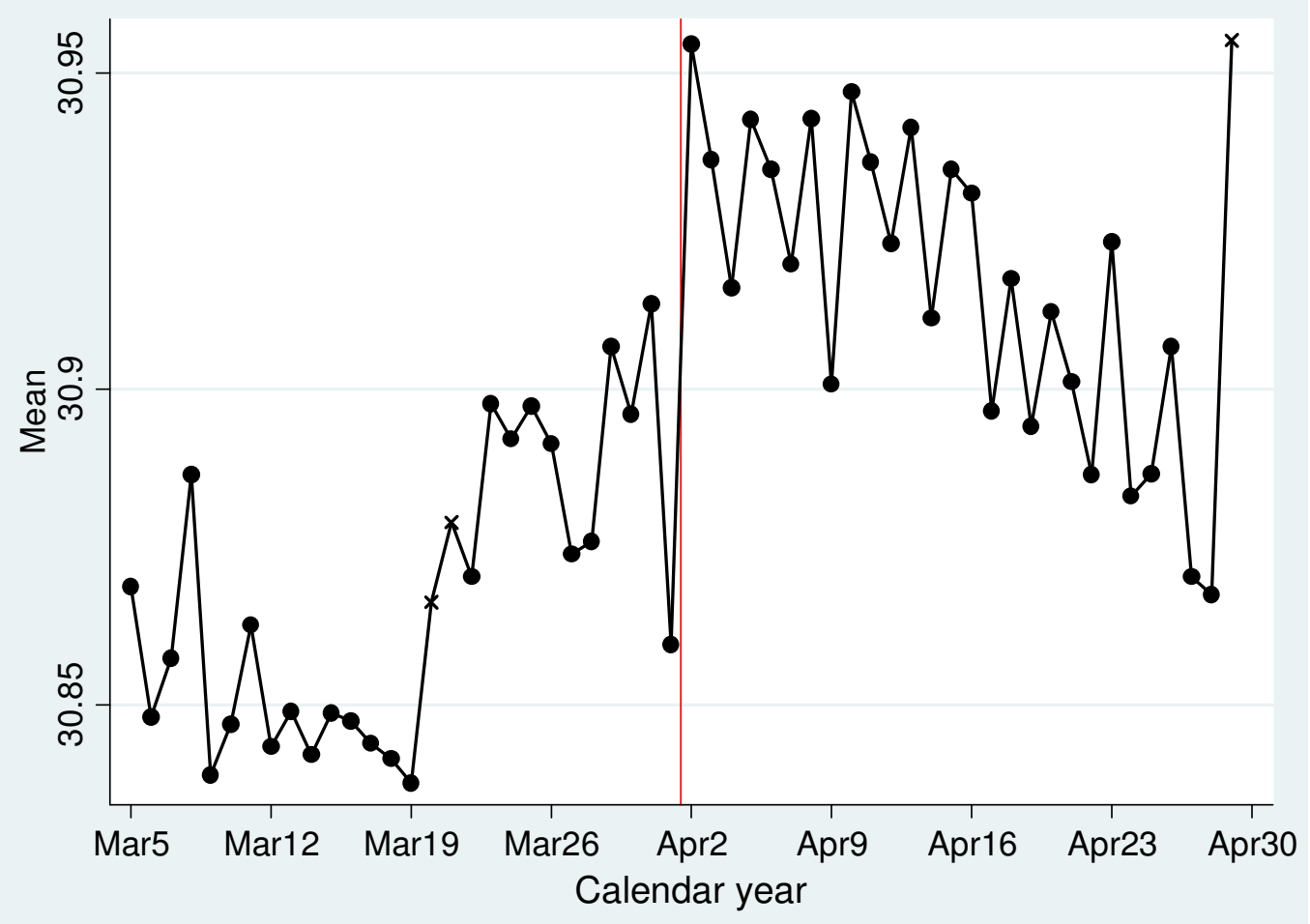

B. Fraction of above 4,000 grams

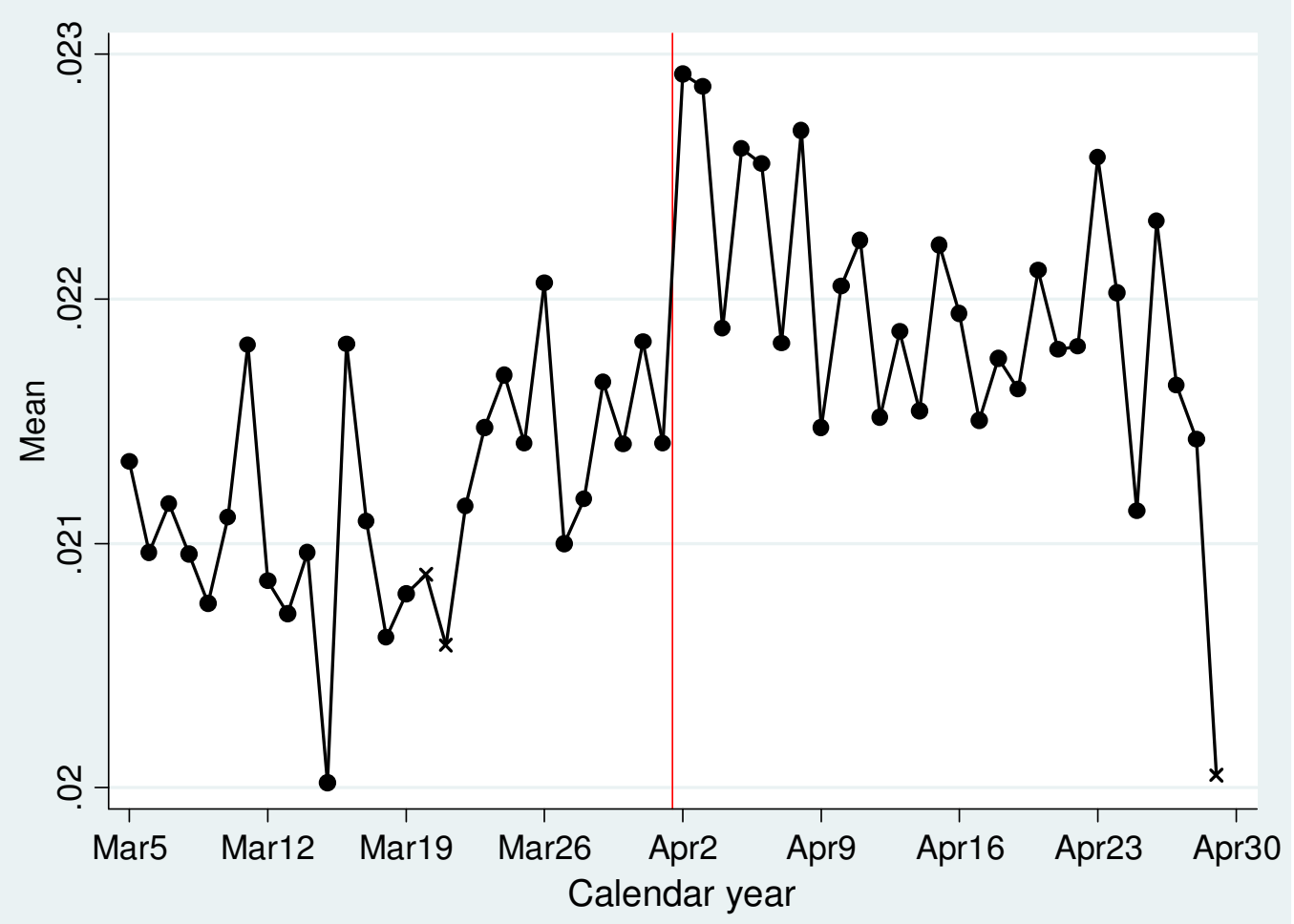




\section{Infant mortality}

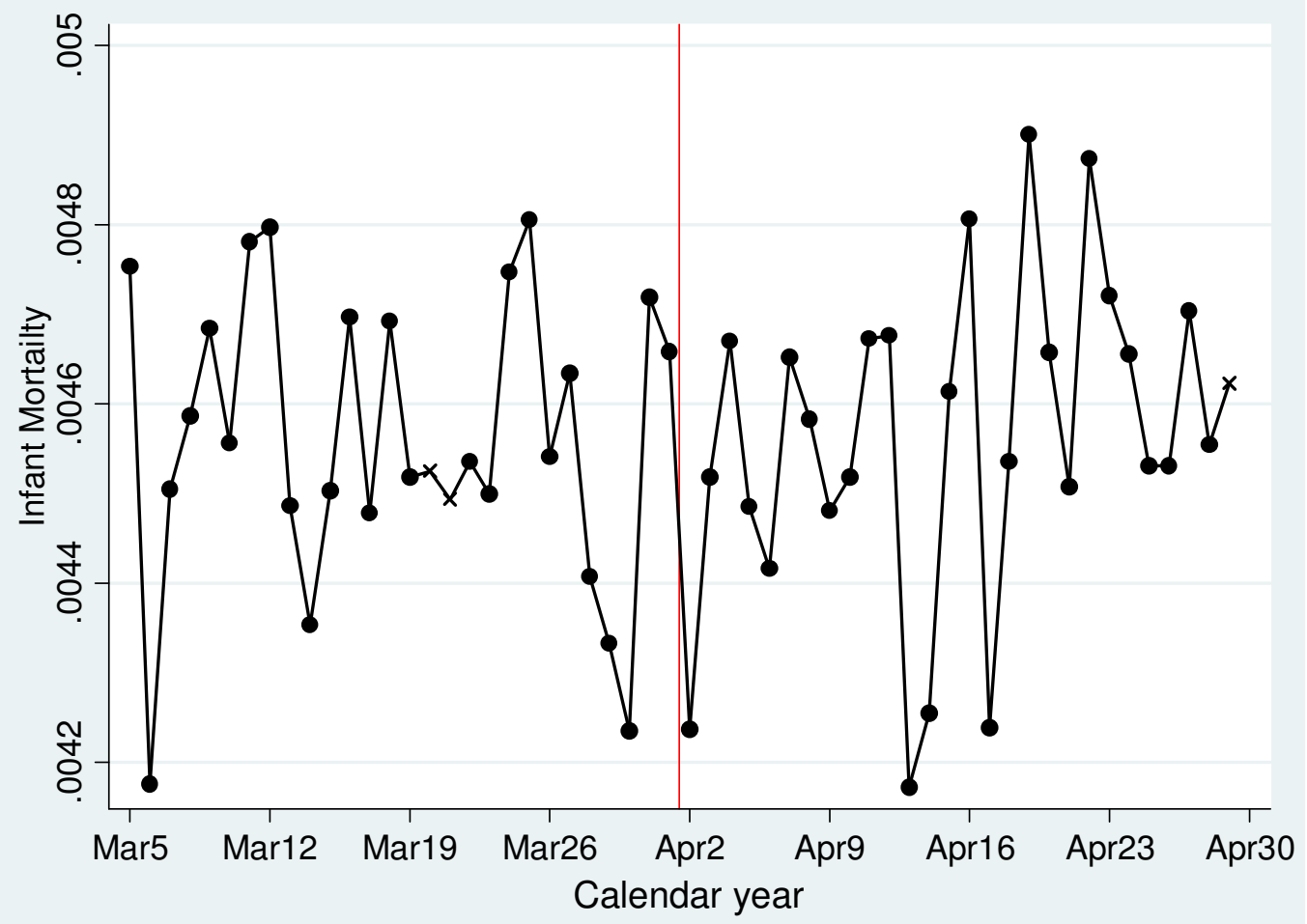

Note: The vertical line corresponds to April 2, which is the school entrance cut-off day in Japan. The data come from pooled 1974-2010 birth data. Each plot is the mean of outcome in each day. The markers with cross sign are holidays. 
Figure 9: Monthly plot of mother's observable characteristics

A. Fraction of mothers working

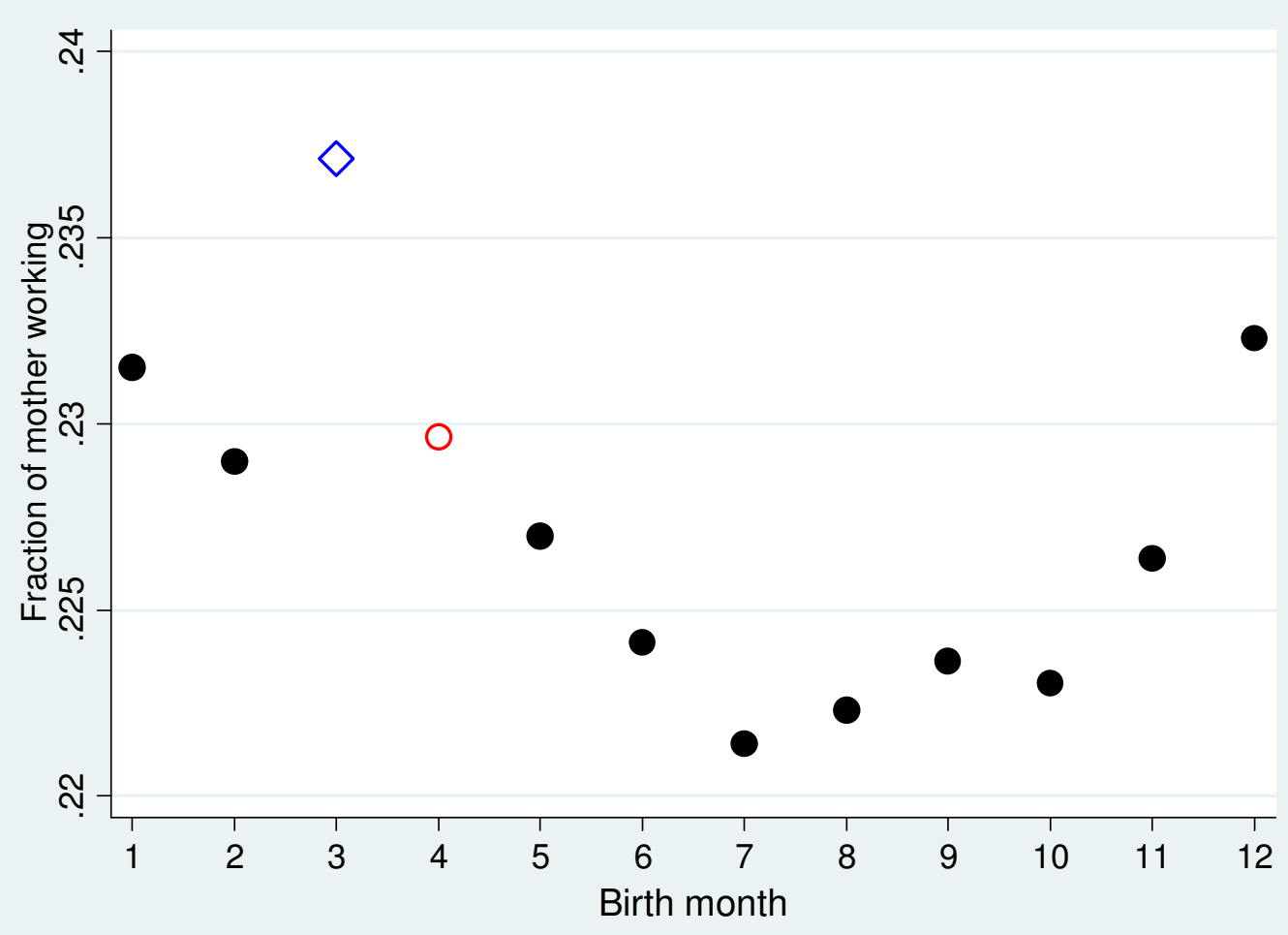

B. Fraction of mothers with low skilled job

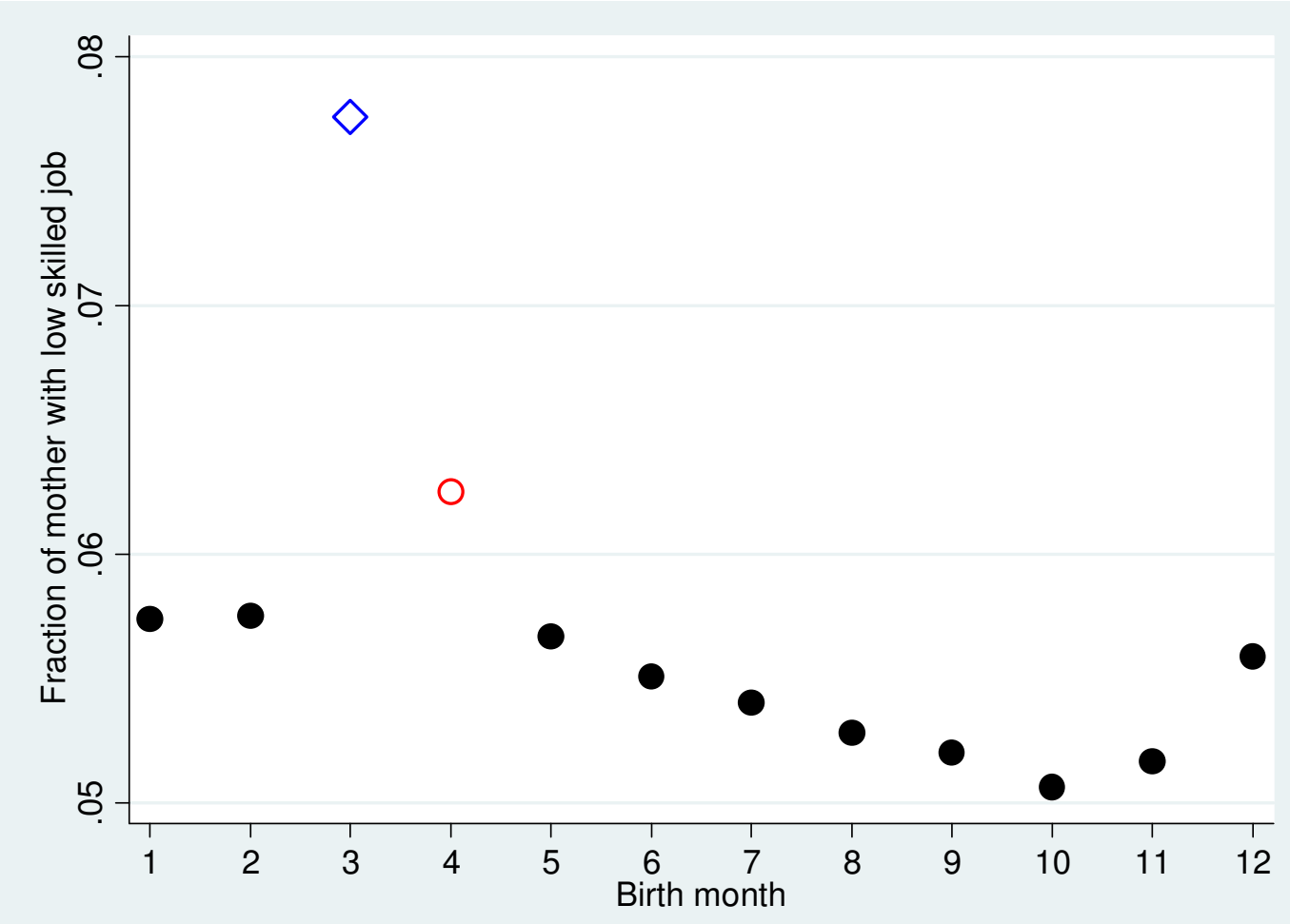

Note: The data come from 1975, 1980, 1985, 1990, 1995, 2000, and 2005 pooled birth data. Each plot is the mean of outcome in each month. The markers in square are March, and those in circle are April. 
Table 1: Top 5 and bottom 5 of mean daily birth within a year

\begin{tabular}{lccc}
\hline \hline & Date & Mean daily births & Ratio to average \\
\hline Top 5 & & & \\
& April 2 & $\mathbf{4 , 4 6 5}$ & $\mathbf{1 . 2 0}$ \\
& Sep 25 & 4,143 & 1.12 \\
& Dec 25 & 4,122 & 1.11 \\
& Sep 26 & 4,119 & 1.11 \\
& April 3 & $\mathbf{4 , 0 8 5}$ & $\mathbf{1 . 1 0}$ \\
\hline Bottom 5 & & & \\
& Feb 29 & 2,452 & 0.66 \\
& Dec 31 & 2,757 & 0.74 \\
& April 1 & $\mathbf{2 , 7 9 1}$ & $\mathbf{0 . 7 5}$ \\
& Jan 2 & 2,798 & 0.75 \\
& Jan 1 & 2,862 & 0.77
\end{tabular}

Notes: The ratio to the average is daily births divided by the mean daily births. Therefor a value of 1.1 represents a 10 percent increase in the daily births compared to the average in the year. Mean daily births during 1974-2010 are 3,713. Solid ones are within a week from April 2.

Table 2: Shift of births

\begin{tabular}{lcccc}
\hline \multirow{2}{*}{ Windows } & $(1)$ & $(2)$ & $(3)$ & $(4)$ \\
\cline { 2 - 5 } Panel A: Number of births & \pm 7 days & \pm 14 days & \pm 21 days & \pm 28 days \\
After & $524.2^{* * *}$ & $268.6^{* * *}$ & $178.9 * * *$ & $166.2^{* * * *}$ \\
& $(55.1)$ & $(30.0)$ & $(20.4)$ & $(16.5)$ \\
Number of births moved & 1,835 & 1,880 & 1,879 & 2,327 \\
$\mathrm{~N}$ & 518 & 1,036 & 1,554 & 2,072 \\
R2 & 0.83 & 0.86 & 0.89 & 0.90 \\
\hline Panel B:In(number of births) & & & & \\
After & $0.136^{* * *}$ & $0.070 * * *$ & $0.047 * * *$ & $0.043 * * *$ \\
& $(0.009)$ & $(0.005)$ & $(0.004)$ & $(0.003)$ \\
Share of births moved & $7.0 \%$ & $3.6 \%$ & $2.4 \%$ & $2.2 \%$ \\
$\mathrm{~N}$ & 518 & 1,036 & 1,554 & 2,072 \\
R2 & 0.86 & 0.88 & 0.90 & 0.91 \\
\hline
\end{tabular}

Notes: Coefficient on After is reported. After takes one if the birthday is after April 2 in each year. Standard errors in parenthesis. ${ }^{*} \mathrm{p}<0.10, * * \mathrm{p}<0.05, * * * \mathrm{p}<0.01$. Sample is daily births within the relevant window from 1974-2010. All specifications include public holiday, and year*day of week fixed effects. Window denotes the number of days before and after April 2. For example, the \pm 7 day window covers the seven days prior to April 2, and the first seven days after April 2. Number of births moved is $W \beta / 2$, where $W$ is the number of days in the window. Share of births moved is $\exp (\beta / 2)-1$. 
Table 3: Heterogeneous response, by mother's and children's characteristics

\begin{tabular}{|c|c|c|c|c|c|c|}
\hline & \multicolumn{2}{|c|}{ A. Parity } & \multicolumn{2}{|c|}{ B. Mother's age } & \multicolumn{2}{|c|}{ C. Working status } \\
\hline & 1 st & $\begin{array}{l}\text { 2nd or } \\
\text { above }\end{array}$ & $\begin{array}{c}\text { Less than } \\
30\end{array}$ & $\begin{array}{c}\text { More than } \\
30\end{array}$ & $\begin{array}{c}\text { Not } \\
\text { working }\end{array}$ & Working \\
\hline & (1) & (2) & (3) & (4) & (5) & (6) \\
\hline After & $\begin{array}{c}0.1008 * * * \\
(0.024)\end{array}$ & $\begin{array}{c}0.1643 * * * \\
(0.033)\end{array}$ & $\begin{array}{c}0.1512 * * * \\
(0.029)\end{array}$ & $\begin{array}{c}0.1091 * * * \\
(0.028)\end{array}$ & $\begin{array}{c}0.2146 * * * \\
(0.022)\end{array}$ & $\begin{array}{l}0.0697^{*} \\
(0.038)\end{array}$ \\
\hline Share of births moved & $5.2 \%$ & $8.6 \%$ & $7.9 \%$ & $5.6 \%$ & $11.3 \%$ & $3.5 \%$ \\
\hline $\mathrm{N}$ & 518 & 518 & 518 & 518 & 98 & 98 \\
\hline R2 & 0.952 & 0.951 & 0.982 & 0.945 & 0.950 & 0.731 \\
\hline \multirow[t]{4}{*}{ Mean of daily births } & 1,645 & 1,938 & 2,253 & 1,330 & 2,689 & 880 \\
\hline & \multicolumn{3}{|c|}{ D. Type of job } & \multicolumn{2}{|c|}{ E. Gender of birth } & \\
\hline & $\begin{array}{l}\text { High } \\
\text { skilled }\end{array}$ & $\begin{array}{l}\text { Medium } \\
\text { skilled }\end{array}$ & Low skilled & Female & Male & \\
\hline & (7) & (8) & (9) & (10) & (11) & \\
\hline After & $\begin{array}{c}0.3775^{* * *} \\
(0.044)\end{array}$ & $\begin{array}{c}0.3741 * * * \\
(0.035)\end{array}$ & $\begin{array}{c}-0.3842 * * * \\
(0.104)\end{array}$ & $\begin{array}{c}0.1179 * * * \\
(0.029) \\
\end{array}$ & $\begin{array}{c}0.1534 * * * \\
(0.029) \\
\end{array}$ & \\
\hline Share of births moved & $20.8 \%$ & $20.6 \%$ & $-17.5 \%$ & $6.1 \%$ & $8.0 \%$ & \\
\hline$N$ & 98 & 98 & 98 & 518 & 518 & \\
\hline R2 & 0.864 & 0.938 & 0.637 & 0.948 & 0.952 & \\
\hline Mean of daily births & 200 & 376 & 333 & 1,740 & 1,843 & \\
\hline
\end{tabular}

Notes: Coefficient on After is reported. After takes one if the birthday is after April 2 in each year. Standard errors in parenthesis. * $\mathrm{p}<0.10, * * \mathrm{p}<0.05, * * * \mathrm{p}<0.01$. Sample for Panel A, B and E is daily births from 1974-2010. Sample for Panel C and D is daily births from 1975, 1980, 1985, 1990, 1995, 2000, and 2005 pooled birth data. The window is restricted to the seven days prior to April 2, and the first seven days after April 2. All specifications include public holiday, and year*day of week fixed effects. Share of births moved is $\exp (\beta / 2)-1$.

Table 4: Child's characteristics

\begin{tabular}{lcccc}
\hline \hline & $\begin{array}{c}\text { Birth weight } \\
(100 \mathrm{~g})\end{array}$ & $\begin{array}{c}\text { Birth } \\
\text { weight }>4000 \mathrm{~g}\end{array}$ & $\begin{array}{c}\text { Gestation>42 } \\
\text { wks }\end{array}$ & $\begin{array}{c}\text { Mortality (per } \\
1000 \text { births) }\end{array}$ \\
& $(1)$ & $(2)$ & $(3)$ & $(4)$ \\
\hline After & $0.023^{* * *}$ & $0.0005^{* * *}$ & $0.0007 * * *$ & -0.090 \\
& $(0.005)$ & $(0.0002)$ & $(0.0002)$ & $(0.090)$ \\
\hline $\mathrm{N} 2$ & $1,847,984$ & $1,847,984$ & $1,846,441$ & 518 \\
Mean & 0.014 & 0.004 & 0.011 & 0.883 \\
\hline
\end{tabular}

Notes: Coefficient on After is reported. After takes one if the birthday is after April 2 in each year. Standard errors in parenthesis. * $\mathrm{p}<0.10,{ }^{* *} \mathrm{p}<0.05, * * * \mathrm{p}<0.01$ significant at $1 \%$. Sample is individual birth from pooled 1974-2010 birth data. All specifications include public holiday, and year*day of week fixed effects. The window is restricted to the seven days prior to April 2, and the first seven days after April 2. 
Table 5: Magnitude of Shifts and Capacity of Child Care Centers

\begin{tabular}{lcccc}
\hline \hline & $(1)$ & $(2)$ & $(3)$ & $(4)$ \\
\cline { 2 - 5 } & $\begin{array}{c}\text { Without } \\
\text { controls }\end{array}$ & $\begin{array}{c}\text { With } \\
\text { controls }\end{array}$ & Weight & $\begin{array}{c}\text { Exclude Tokyo } \\
\text { and Osaka }\end{array}$ \\
\hline Capacity & $0.140^{* * *}$ & $0.146^{* * *}$ & $0.112^{* * *}$ & $0.111^{* * *}$ \\
$\mathrm{~N}$ & $(0.032)$ & $(0.035)$ & $(0.020)$ & $(0.032)$ \\
$\mathrm{R} 2$ & 1,598 & 1,597 & 1,597 & 1,529 \\
\hline Year fixed effects & 0.447 & 0.448 & 0.538 & 0.523 \\
Prefecture fixed effects & $\mathrm{X}$ & $\mathrm{X}$ & $\mathrm{X}$ & $\mathrm{X}$ \\
Controls & $\mathrm{X}$ & $\mathrm{X}$ & $\mathrm{X}$ & $\mathrm{X}$ \\
Weight & & $\mathrm{X}$ & $\mathrm{X}$ & $\mathrm{X}$ \\
Without Tokyo and Osaka & & & $\mathrm{X}$ & $\mathrm{X}$ \\
\hline
\end{tabular}

Notes: Coefficient on capacity is reported. Capacity is defined as the total slots of the day-care centers (i.e. total capacity of day-care centers) divided by the total number of females between ages 20-39, the child-bearing age. Other controls include the real GDP per capita which is deflated by prefecture GDP deflator to Yen in 2000, job application-to-opening ratio at October of year $y-1$ (a year prior to March/April when the shifts of births occur in year $y$ ), application-to-opening ratio in March of the year $y$. Weight uses the mean daily number of births at each prefecture/year cell. Tokyo and Osaka are two largest prefectures in Japan. Standard errors in parenthesis. * $\mathrm{p}<0.10$, $* * \mathrm{p}<0.05, * * * \mathrm{p}<0.01$ 
Table 6: Magnitude of the timing of shifts from other studies

\begin{tabular}{|c|c|c|c|c|c|}
\hline Authors & Policy & Country & Incentives & $\begin{array}{l}\text { Could policy } \\
\text { also affect } \\
\text { conceptions? }\end{array}$ & $\begin{array}{l}\text { Share of } \\
\text { births } \\
\text { moved }\end{array}$ \\
\hline Dickert-Conlin and Chandra (1999) & Tax changes from 1979-1993 & US & Hasten & Yes & $13.6 \%$ \\
\hline Gans and Leigh (2009) & Baby Bonus introduction in 2004 & Australia & Delay & No & $16.2 \%$ \\
\hline Gans and Leigh (2009) & Baby Bonus increase in 2006 & Australia & Delay & Yes & $9.2 \%$ \\
\hline Tamm (2012) & Parental leave benefit reform in 2006/2007 & Germany & Delay & Yes & $7.8 \%$ \\
\hline Neugart and Ohlsson (2013) & Parental leave benefit reform in 2006/2007 & Germany & Delay & Yes & $5.4 \%$ \\
\hline Shigeoka (2013) & School entrance cut-off dates from 1974-2010 & Japan & Both & Yes & $7.0 \%$ \\
\hline
\end{tabular}

Note: The share of birth moved in the last column is based on the estimates from a 7-days window from the cut-off dates. 


\section{Appendix Figures and Tables}


Figure A: Mean daily number of births through the year, by parity

A. $1^{\text {st }}$ and $2^{\text {nd }}$ or above

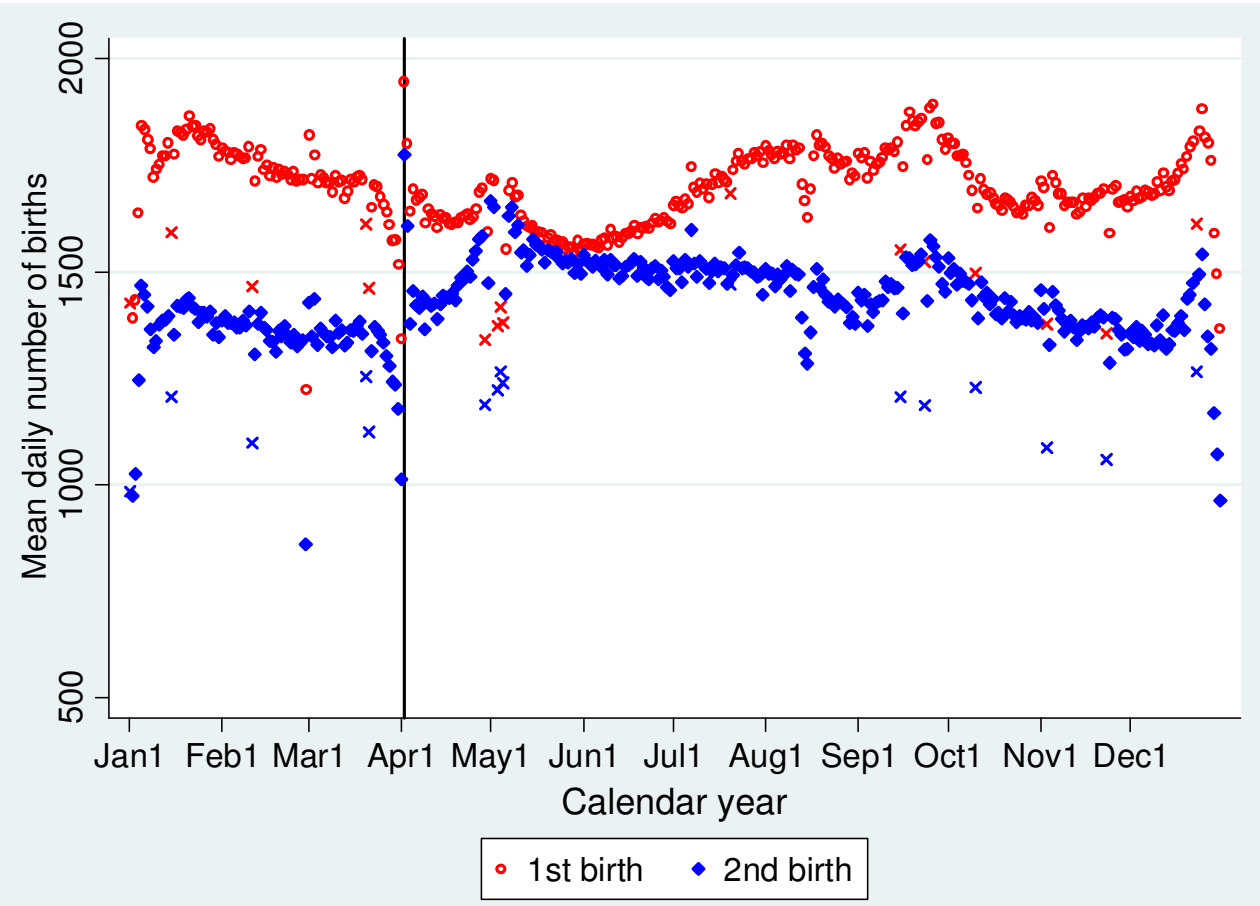

B. Fraction of $2^{\text {nd }}$ birth among all births

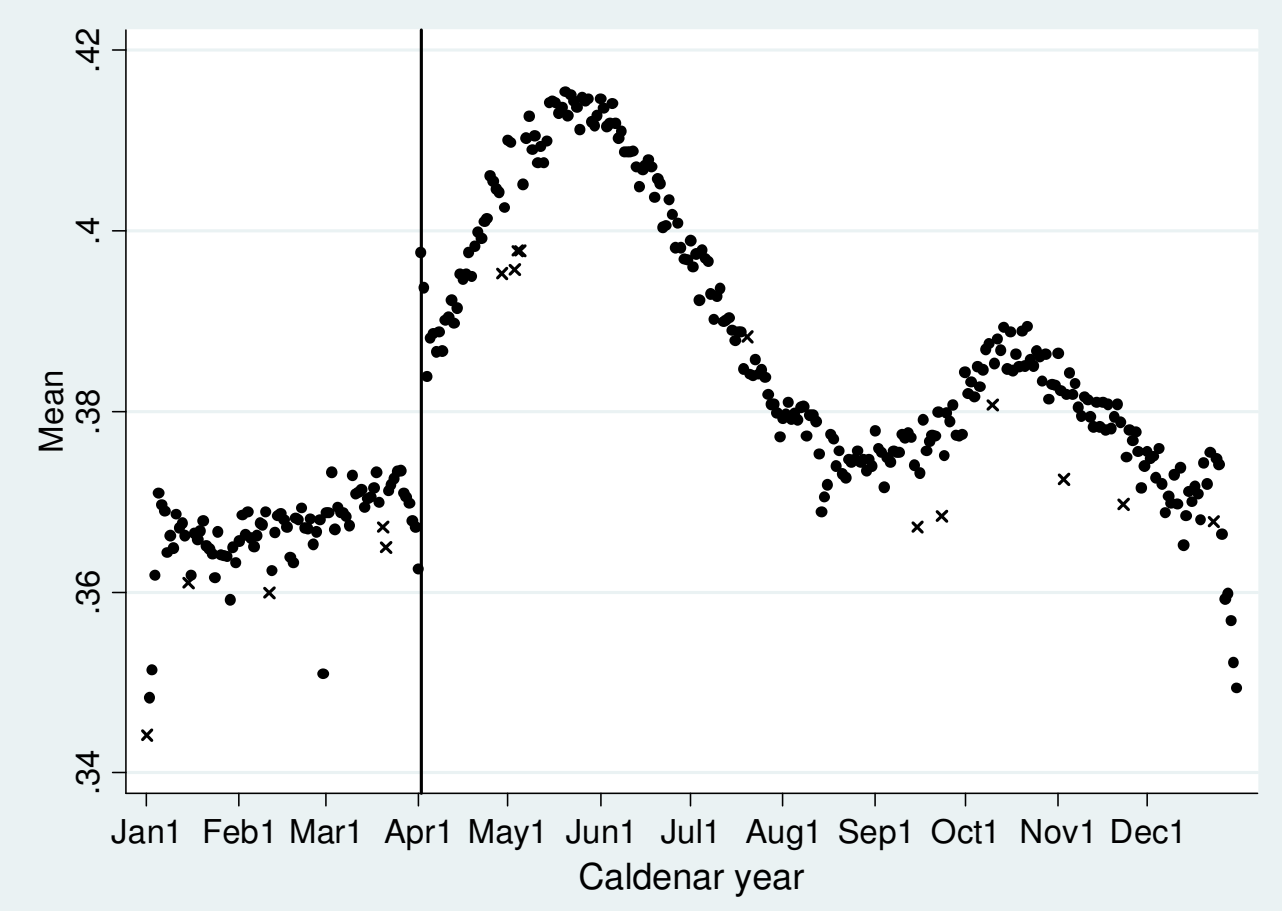

Note: The vertical line corresponds to April 2, which is the school entrance cut-off day in Japan. The data come from pooled 1974-2010 birth data. The markers with cross sign are holidays. 
Figure B: Mean daily number of births around April 2, by period

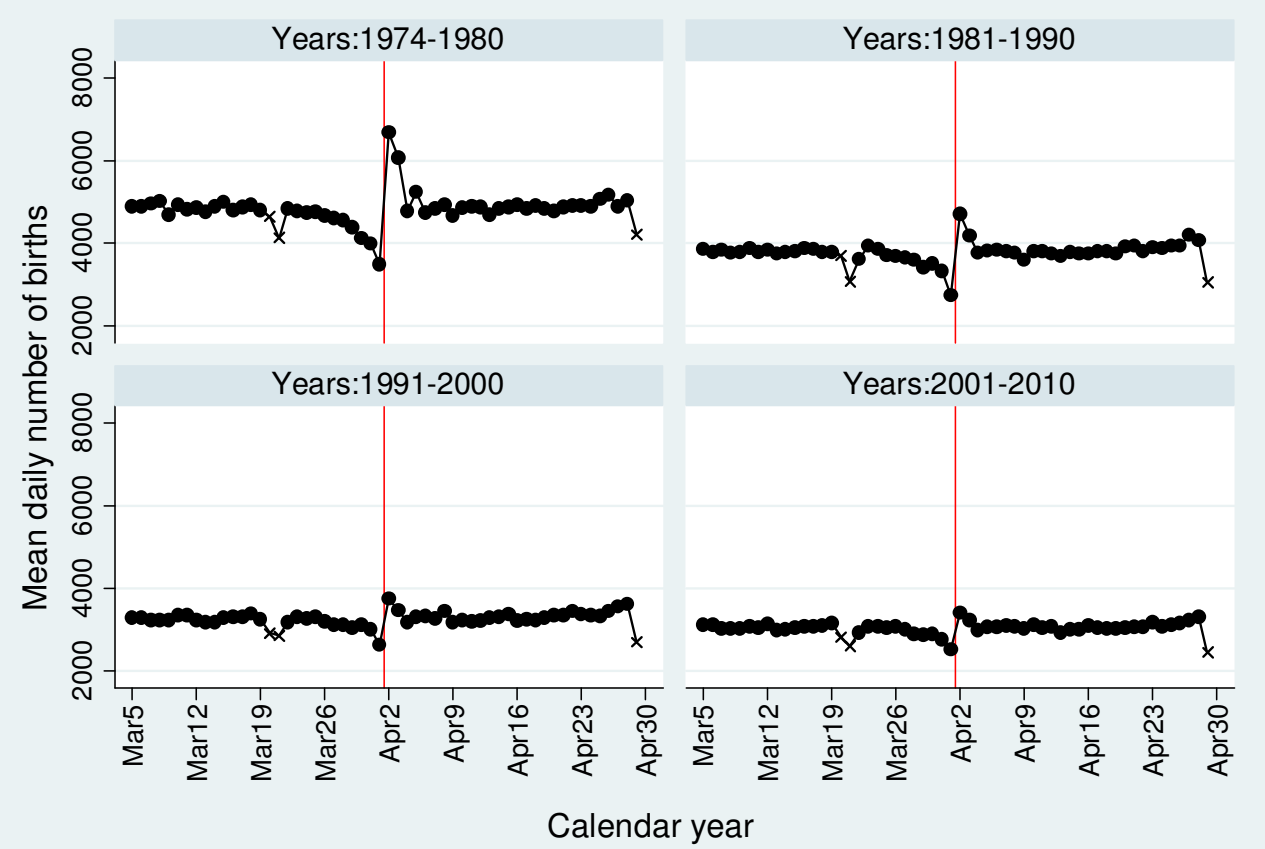

Note: The vertical line corresponds to April 2, which is the school entrance cut-off day in Japan. The data come from pooled 1974-2010 birth data. The markers with cross sign are holidays. Each plot is the number of births in each day.

Figure C: Share of births moved by each birth year

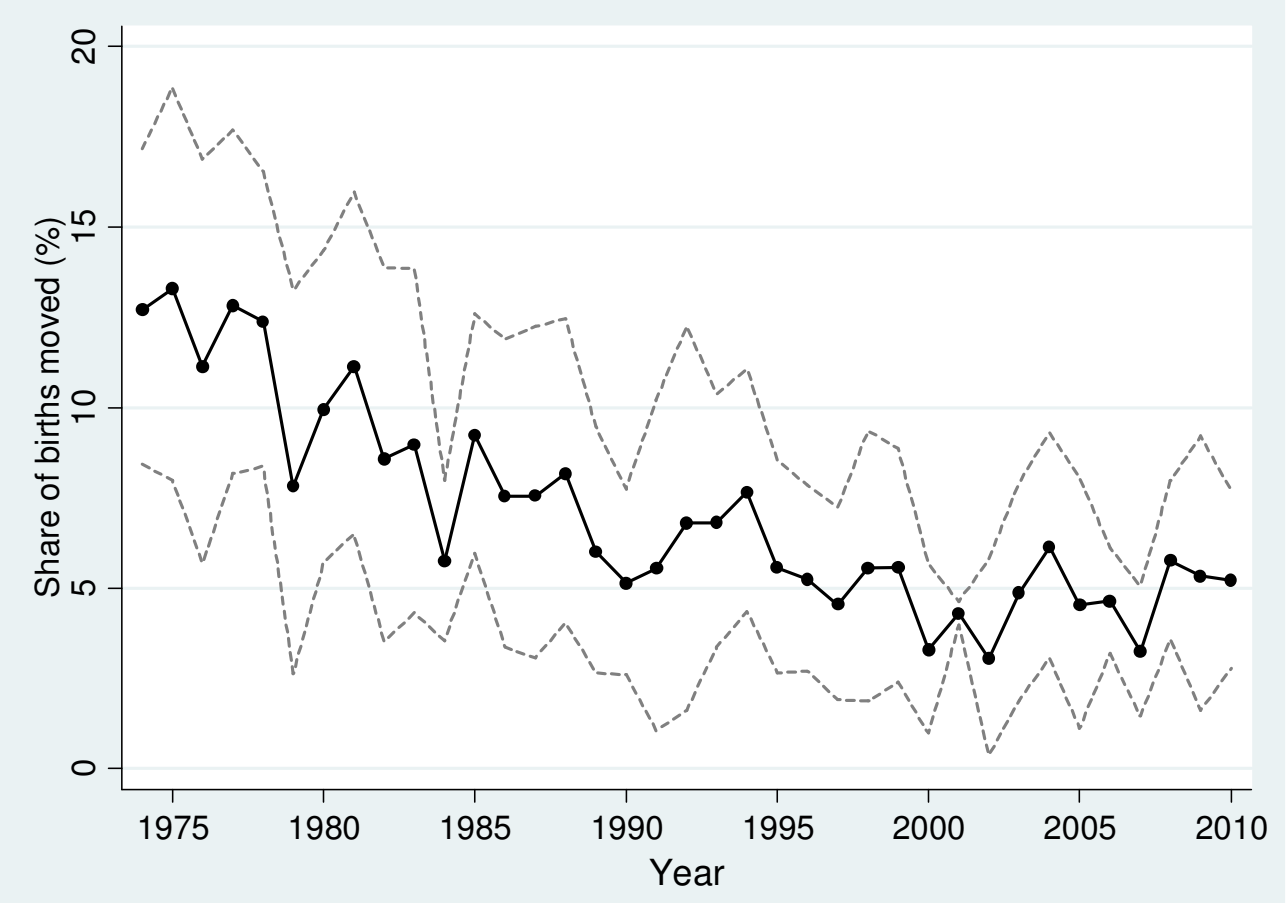

Note: The data come from 1974-2010 birth data. The dotted line represents $95 \%$ confidence interval. 
Figure D: Heterogeneous responses: Mother's employment, by period A. Working vs. Non-working mothers

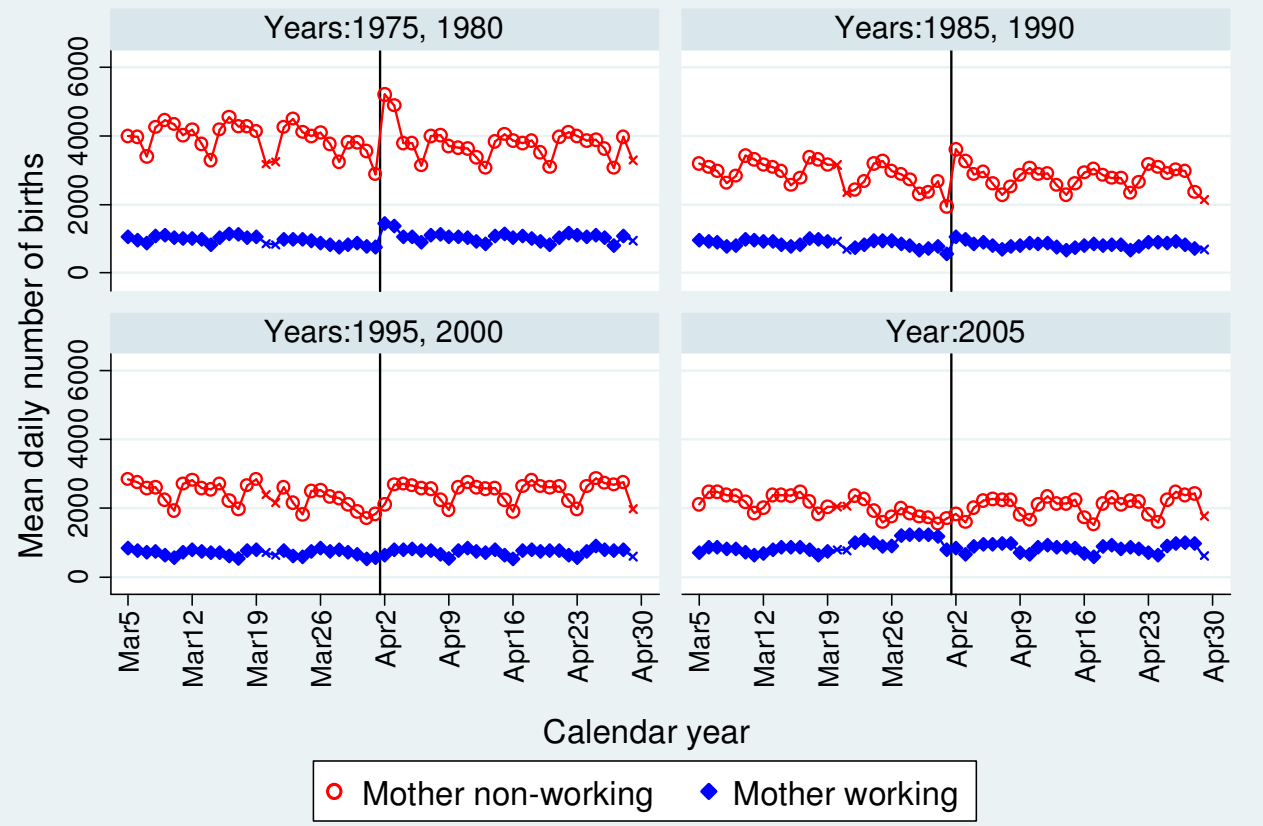

B. Among working mothers: Type of jobs

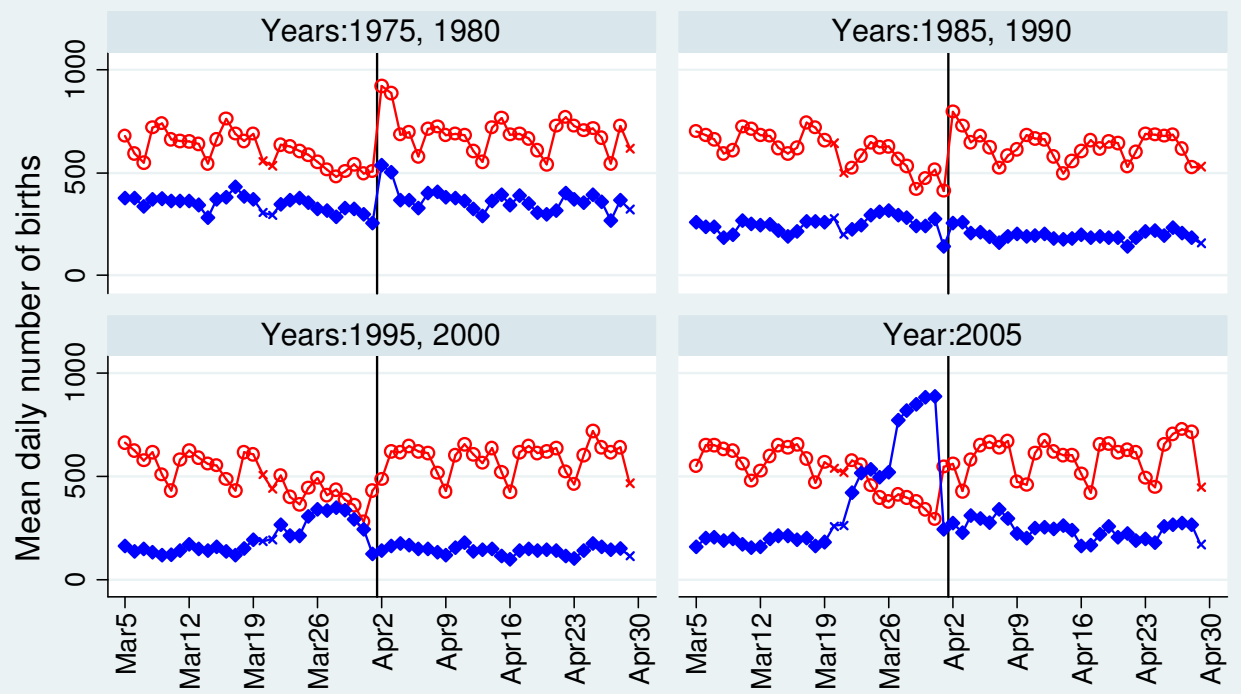

Calendar year

\section{- High paid job • Low paid job}

Note: The sold vertical line corresponds to April 2, which is the school entrance cut-off day in Japan. Sample is daily births within the relevant window from 1975, 1980, 1985, 1990, 1995, 2000, and 2005 pooled birth data. Each plot is the number of births in each day. The markers with cross sign are holidays. 
Table A: Type of mother's job

\begin{tabular}{cl}
\hline \hline Skill level & Description \\
\hline High skilled & Managers \\
& Professionals \\
\hline Medium skilled & Clerical support workers \\
& Service and sales workers \\
\hline Low skilled & Skilled agricultural, forestry and fishery workers \\
& Craft and related trades workers \\
& Plant and machine operators, and assemblers \\
& Elementary occupations \\
\hline
\end{tabular}

Table B: Summary statistics

\begin{tabular}{|c|c|c|c|c|}
\hline & $\begin{array}{c}7 \text { days } \\
\text { before } \\
\text { cut-off date }\end{array}$ & $\begin{array}{c}7 \text { days } \\
\text { after } \\
\text { cut-off date }\end{array}$ & $\begin{array}{l}\text { Dif } \\
(2)-(1)\end{array}$ & $\begin{array}{c}\text { Entire } \\
\text { year }\end{array}$ \\
\hline & (1) & (2) & (3) & (4) \\
\hline \multicolumn{5}{|l|}{ A. Mother characteristics } \\
\hline Age (in years) & 29.84 & 29.75 & $-0.091 * * *$ & 29.81 \\
\hline Working & 0.26 & 0.23 & $-0.030 * * *$ & 0.23 \\
\hline High Skilled job & 0.04 & 0.05 & $0.009 * * *$ & 0.06 \\
\hline Medium Skilled job & 0.10 & 0.11 & $0.019 * * *$ & 0.11 \\
\hline Low skilled job & 0.13 & 0.07 & $-0.058 * * *$ & 0.06 \\
\hline \multicolumn{5}{|l|}{ B. Child characteristics } \\
\hline 1st birth & 0.47 & 0.45 & $-0.020 * * *$ & 0.46 \\
\hline 2nd birth & 0.37 & 0.39 & $0.021 * * *$ & 0.38 \\
\hline Birth weight (in 1000 grams) & 30.89 & 30.94 & $0.047 * * *$ & 30.89 \\
\hline Birth weight (>3500 grams) & 0.1783 & 0.1819 & $0.0037 * * *$ & 0.1785 \\
\hline Birth weight ( $>4000$ grams) & 0.0215 & 0.0225 & $0.0010^{* * *}$ & 0.0216 \\
\hline Birth weight (>4500 grams) & 0.0017 & 0.0018 & $0.0001 *$ & 0.0017 \\
\hline Gestational length (weeks) & 39.21 & 39.23 & $0.017 *$ & 39.20 \\
\hline Delivered at hospital & 0.54 & 0.52 & $-0.021 * * *$ & 0.53 \\
\hline Delivered at clinic & 0.43 & 0.45 & $0.016 * * *$ & 0.44 \\
\hline Delivered at home & 0.003 & 0.004 & $0.0005^{* *}$ & 0.003 \\
\hline Infant mortality & 0.0042 & 0.0041 & -0.0001 & 0.0042 \\
\hline Mean daily number of births & 3,321 & 3,845 & $524 * * *$ & 3,713 \\
\hline
\end{tabular}

Note: $* \mathrm{p}<0.10, * * \mathrm{p}<0.05, * * * \mathrm{p}<0.01$ significant at $1 \%$. The data come from pooled 1974-2010 birth data except for working, high skilled job, medium skilled job, low skilled job, which come from 1975, 1980, 1985, 1990, 1995, 2000, and 2005 pooled birth data. Colum (1) is mean from the sample in seven days prior to April 2, and Column (2) is mean from sample in the first seven days after April 2, and Colum (3) is difference between (2) and (1). Column (4) is the mean from data that cover entire year. 
Table C: Heterogeneous responses by mother's characteristics

\begin{tabular}{|c|c|c|c|c|c|c|}
\hline & & & $(1)$ & $(2)$ & $(3)$ & $(4)$ \\
\hline & & Mean & \pm 7 days & \pm 14 days & \pm 21 days & \pm 28 days \\
\hline \multicolumn{7}{|l|}{ A. Parity } \\
\hline \multirow[t]{4}{*}{ 1st child } & After & 1,645 & $0.101 * * *$ & $0.036^{*}$ & 0.007 & -0.003 \\
\hline & & & $(0.024)$ & $(0.022)$ & $(0.016)$ & $(0.012)$ \\
\hline & $\mathrm{R} 2$ & & 0.952 & 0.889 & 0.890 & 0.895 \\
\hline & Share of births moved & & $5.2 \%$ & $1.8 \%$ & $0.4 \%$ & $-0.2 \%$ \\
\hline \multirow{4}{*}{$\begin{array}{l}\text { 2nd child or } \\
\text { above }\end{array}$} & After & 1,938 & $0.164 * * *$ & $0.097 * * *$ & $0.078 * * *$ & $0.078 * * *$ \\
\hline & & & $(0.033)$ & $(0.028)$ & $(0.020)$ & $(0.015)$ \\
\hline & $\mathrm{R} 2$ & & 0.951 & 0.916 & 0.925 & 0.929 \\
\hline & Share of births moved & & $8.6 \%$ & $5.0 \%$ & $4.0 \%$ & $4.0 \%$ \\
\hline \multicolumn{7}{|l|}{ B. Mother's age } \\
\hline \multirow[t]{4}{*}{ Less than 30} & After & 2,253 & $0.151 * * *$ & $0.084 * * *$ & $0.059 * * *$ & $0.053 * * *$ \\
\hline & & & $(0.029)$ & $(0.025)$ & $(0.018)$ & $(0.013)$ \\
\hline & $\mathrm{R} 2$ & & 0.982 & 0.967 & 0.971 & 0.974 \\
\hline & Share of births moved & & $7.9 \%$ & $4.3 \%$ & $3.0 \%$ & $2.7 \%$ \\
\hline \multirow[t]{5}{*}{ Above 30} & After & 1,330 & $0.109 * * *$ & $0.048 * *$ & $0.028 *$ & $0.027 * *$ \\
\hline & & & $(0.028)$ & $(0.024)$ & $(0.017)$ & $(0.013)$ \\
\hline & $\mathrm{R} 2$ & & 0.945 & 0.893 & 0.902 & 0.906 \\
\hline & Share of births moved & & $5.6 \%$ & $2.4 \%$ & $1.4 \%$ & $1.4 \%$ \\
\hline & $\mathrm{N}$ & & 518 & 1,036 & 1,554 & 2,072 \\
\hline \multicolumn{7}{|l|}{ C. Working status } \\
\hline \multirow[t]{4}{*}{ Not working } & After & 2,689 & $0.215 * * *$ & $0.140 * * *$ & $0.099 * * *$ & $0.0829 * * *$ \\
\hline & & & $(0.022)$ & $(0.026)$ & $(0.022)$ & $(0.018)$ \\
\hline & R2 & & 0.950 & 0.909 & 0.904 & 0.906 \\
\hline & Share of births moved & & $11.3 \%$ & $7.2 \%$ & $5.1 \%$ & $4.2 \%$ \\
\hline \multirow[t]{4}{*}{ Working } & After & 880 & $0.070^{*}$ & 0.032 & 0.028 & $0.034 * * *$ \\
\hline & & & $(0.038)$ & $(0.023)$ & $(0.017)$ & $(0.013)$ \\
\hline & $\mathrm{R} 2$ & & 0.731 & 0.714 & 0.733 & 0.758 \\
\hline & Share of births moved & & $3.5 \%$ & $1.6 \%$ & $1.4 \%$ & $1.7 \%$ \\
\hline \multicolumn{7}{|l|}{ D. Type of job } \\
\hline \multirow[t]{4}{*}{ High skilled } & After & 200 & $0.378 * * *$ & $0.257 * * *$ & $0.175 * * *$ & $0.136 * * *$ \\
\hline & & & $(0.044)$ & $(0.047)$ & $(0.044)$ & $(0.037)$ \\
\hline & $\mathrm{R} 2$ & & 0.864 & 0.670 & 0.560 & 0.530 \\
\hline & Share of births moved & & $20.8 \%$ & $13.7 \%$ & $9.1 \%$ & $7.0 \%$ \\
\hline \multirow[t]{4}{*}{ Medium skilled } & After & 376 & $0.374 * * *$ & $0.258 * * *$ & $0.170 * * *$ & $0.133 * * *$ \\
\hline & & & $(0.035)$ & $(0.039)$ & $(0.037)$ & $(0.030)$ \\
\hline & $\mathrm{R} 2$ & & 0.938 & 0.872 & 0.836 & 0.836 \\
\hline & Share of births moved & & $20.6 \%$ & $13.7 \%$ & $8.9 \%$ & $6.9 \%$ \\
\hline \multirow[t]{5}{*}{ Low skilled } & After & 333 & $-0.384 * * *$ & $-0.344 * * *$ & $-0.213 * * *$ & $-0.127 * *$ \\
\hline & & & $(0.104)$ & $(0.065)$ & $(0.074)$ & $(0.061)$ \\
\hline & $\mathrm{R} 2$ & & 0.637 & 0.628 & 0.580 & 0.599 \\
\hline & Share of births moved & & $-17.5 \%$ & $-15.8 \%$ & $-10.1 \%$ & $-6.2 \%$ \\
\hline & $\mathrm{N}$ & & 98 & 196 & 294 & 392 \\
\hline
\end{tabular}


Table D: Heterogeneous response, by gender/parity of child

\begin{tabular}{|c|c|c|c|c|c|c|}
\hline \multirow{2}{*}{ Windows } & & \multirow[b]{2}{*}{ Mean } & \multirow{2}{*}{$\frac{(1)}{ \pm 7 \text { days }}$} & \multirow{2}{*}{$\frac{(2)}{ \pm 14 \text { days }}$} & \multirow{2}{*}{$\frac{(3)}{ \pm 21 \text { days }}$} & \multirow{2}{*}{$\begin{array}{c}(4) \\
\pm 28 \text { days }\end{array}$} \\
\hline & & & & & & \\
\hline \multicolumn{7}{|l|}{ A: All births } \\
\hline \multirow[t]{4}{*}{ Female } & After & 1,740 & $0.118 * * *$ & $0.059 * *$ & $0.0379 * *$ & $0.035 * * *$ \\
\hline & & & $(0.029)$ & $(0.024)$ & $(0.017)$ & $(0.013)$ \\
\hline & $\mathrm{R} 2$ & & 0.948 & 0.909 & 0.918 & 0.923 \\
\hline & Share of births moved & & $6.1 \%$ & $3.0 \%$ & $1.9 \%$ & $1.8 \%$ \\
\hline \multirow[t]{4}{*}{ Male } & After & 1,843 & $0.153 * * *$ & $0.081 * * *$ & $0.056 * * *$ & $0.050 * * *$ \\
\hline & & & $(0.029)$ & $(0.027)$ & $(0.019)$ & $(0.014)$ \\
\hline & $\mathrm{R} 2$ & & 0.952 & 0.899 & 0.909 & 0.917 \\
\hline & Share of births moved & & $8.0 \%$ & $4.1 \%$ & $2.8 \%$ & $2.5 \%$ \\
\hline \multicolumn{7}{|l|}{$B: 1^{s t}$ child } \\
\hline \multirow[t]{4}{*}{ Female } & After & 799 & $0.084 * * *$ & 0.026 & -0.002 & -0.010 \\
\hline & & & $(0.024)$ & $(0.020)$ & $(0.015)$ & $(0.011)$ \\
\hline & $\mathrm{R} 2$ & & 0.944 & 0.881 & 0.883 & 0.886 \\
\hline & Share of births moved & & $4.3 \%$ & $1.3 \%$ & $-0.1 \%$ & $-0.5 \%$ \\
\hline \multirow[t]{4}{*}{ Male } & After & 846 & $0.117 * * *$ & $0.047 * *$ & 0.016 & 0.003 \\
\hline & & & $(0.024)$ & $(0.023)$ & $(0.017)$ & $(0.013)$ \\
\hline & $\mathrm{R} 2$ & & 0.944 & 0.871 & 0.869 & 0.875 \\
\hline & Share of births moved & & $6.0 \%$ & $2.4 \%$ & $0.8 \%$ & $0.2 \%$ \\
\hline \multicolumn{7}{|c|}{ C: Second or above child } \\
\hline \multirow[t]{4}{*}{ Female } & After & 940 & $0.145^{* * *}$ & $0.085 * * *$ & $0.068 * * *$ & $0.070 * * *$ \\
\hline & & & $(0.033)$ & $(0.027)$ & $(0.019)$ & $(0.015)$ \\
\hline & $\mathrm{R} 2$ & & 0.946 & 0.913 & 0.922 & 0.924 \\
\hline & Share of births moved & & $7.5 \%$ & $4.3 \%$ & $3.4 \%$ & $3.6 \%$ \\
\hline \multirow[t]{5}{*}{ Male } & After & 998 & $0.183 * * *$ & $0.109 * * *$ & $0.088 * * *$ & $0.086 * * *$ \\
\hline & & & $(0.034)$ & $(0.030)$ & $(0.021)$ & $(0.016)$ \\
\hline & $\mathrm{R} 2$ & & 0.950 & 0.907 & 0.916 & 0.921 \\
\hline & Share of births moved & & $9.6 \%$ & $5.6 \%$ & $4.5 \%$ & $4.4 \%$ \\
\hline & $\mathrm{N}$ & & 518 & 1,036 & 1,554 & 2,072 \\
\hline
\end{tabular}

Note: Standard errors in parenthesis. ${ }^{*} \mathrm{p}<0.10,{ }^{*} \mathrm{p}<0.05, * * * \mathrm{p}<0.01$. Sample is daily births within the relevant window from 1975, 1980, 1985, 1990, 1995, 2000, and 2005 pooled birth data. All specifications include public holiday, and year*day of week fixed effects. Window denotes the number of days before and after April 2. For example, the \pm 7 day window covers the seven days prior to April 2, and the first seven days after April 2. Share of births moved is $\exp (\beta / 2)-1$. 
Table E: Child's characteristics

\begin{tabular}{|c|c|c|c|c|c|}
\hline \multirow[b]{2}{*}{ Windows } & \multirow[b]{2}{*}{ Mean } & (1) & (2) & (3) & (4) \\
\hline & & \pm 7 days & \pm 14 days & \pm 21 days & \pm 28 days \\
\hline \multicolumn{6}{|c|}{ A: Birth weight $(100 \mathrm{~g})$} \\
\hline After & \multirow[t]{3}{*}{30.90} & $\begin{array}{c}0.023 * * * \\
(0.005)\end{array}$ & $\begin{array}{c}0.038 * * * \\
(0.007)\end{array}$ & $\begin{array}{c}0.047 * * * \\
(0.007)\end{array}$ & $\begin{array}{c}0.045 * * * \\
(0.007)\end{array}$ \\
\hline $\mathrm{N}$ & & $1,847,984$ & $3,689,329$ & $5,579,356$ & $7,477,055$ \\
\hline $\mathrm{R} 2$ & & 0.014 & 0.014 & 0.014 & 0.014 \\
\hline \multicolumn{6}{|c|}{ B: Birth weight $>4000 \mathrm{~g}$} \\
\hline After & \multirow[t]{3}{*}{0.022} & $\begin{array}{c}0.0005^{* * * *} \\
(0.0002)\end{array}$ & $\begin{array}{c}0.0006^{* * *} * \\
(0.0001)\end{array}$ & $\begin{array}{c}0.0007 * * * \\
(0.0001)\end{array}$ & $\begin{array}{c}0.0007 * * * \\
(0.0001)\end{array}$ \\
\hline $\mathrm{N}$ & & $1,847,984$ & $3,689,329$ & $5,579,356$ & $7,477,055$ \\
\hline R2 & & 0.004 & 0.004 & 0.004 & 0.004 \\
\hline \multicolumn{6}{|l|}{ C: Gestation $>42$ wks } \\
\hline After & \multirow[t]{3}{*}{0.023} & $\begin{array}{c}0.0007 * * * \\
(0.0002)\end{array}$ & $\begin{array}{c}0.0001 \\
(0.0002)\end{array}$ & $\begin{array}{c}0.0003 * * \\
(0.0002)\end{array}$ & $\begin{array}{c}0.0005^{* * * *} \\
(0.0001)\end{array}$ \\
\hline $\mathrm{N}$ & & $1,846,441$ & $3,686,276$ & $5,574,761$ & $7,470,764$ \\
\hline R2 & & 0.011 & 0.010 & 0.010 & 0.009 \\
\hline \multicolumn{6}{|c|}{ D: Mortality per 1000 births } \\
\hline After & 4.155 & $\begin{array}{l}-0.090 \\
(0.090)\end{array}$ & $\begin{array}{l}-0.100 \\
(0.060)\end{array}$ & $\begin{array}{l}-0.030 \\
(0.050)\end{array}$ & $\begin{array}{l}-0.010 \\
(0.050)\end{array}$ \\
\hline $\mathrm{N}$ & & 518 & 1,036 & 1,554 & 2,072 \\
\hline R2 & & 0.883 & 0.844 & 0.826 & 0.817 \\
\hline
\end{tabular}

Notes: Standard errors in parenthesis. $* \mathrm{p}<0.10, * * \mathrm{p}<0.05, * * * \mathrm{p}<0.01$ significant at $1 \%$. Sample is individual birth within the relevant window from pooled 1974-2010 birth data. All specifications include public holiday, and year*day of week fixed effects. Window denotes the number of days before and after the April 2. For example, the \pm 7 day window covers the seven days prior to April 2, and the first seven days after April 2. 
Table F: Source of variables

\begin{tabular}{|c|c|c|c|c|}
\hline Variable name & Years available & Mean & SD & Source \\
\hline $\begin{array}{l}\text { Total slots of } \\
\text { day-care centers }\end{array}$ & $\begin{array}{l}\text { 1974-2007: } \\
\text { yearly level }\end{array}$ & 42,199 & 30,829 & Survey of Social Welfare Institutions \\
\hline $\begin{array}{l}\text { Number of female } \\
\text { population between } \\
\text { ages } 20-39\end{array}$ & $\begin{array}{l}\text { 1970-2010: } \\
\text { every five years }\end{array}$ & 371,624 & 378,970 & Census \\
\hline GDP per capita & $\begin{array}{l}\text { 1974-2009: } \\
\text { yearly level }\end{array}$ & 2,269 & 730 & $\begin{array}{l}\text { Prefecture SNA, available at } \\
\text { http://www.esri.cao.go.jp/jp/sna/data/data_list } \\
\text { /kenmin/files/files_kenmin.html (last accessed } \\
\text { March 11, 2013) }\end{array}$ \\
\hline $\begin{array}{l}\text { Prefecture specific } \\
\text { deflator }\end{array}$ & $\begin{array}{l}\text { 1974-2009: } \\
\text { yearly level }\end{array}$ & 91 & 12 & $\begin{array}{l}\text { Prefecture SNA, available at } \\
\text { http://www.esri.cao.go.jp/jp/sna/data/data_list } \\
\text { /kenmin/files/files_kenmin.html (last accessed } \\
\text { March 11, 2013) }\end{array}$ \\
\hline $\begin{array}{l}\text { Job } \\
\text { application-to-open } \\
\text { ing ratio (Oct) }\end{array}$ & $\begin{array}{l}\text { 1974-2009: } \\
\text { monthly level }\end{array}$ & 0.863 & 0.561 & $\begin{array}{l}\text { Job/employment placement services statistics, } \\
\text { available at } \\
\text { http://www.e-stat.go.jp/SG1/estat/List.do?lid= } \\
\frac{000001108017}{2013)} \text { (last accessed March 11, }\end{array}$ \\
\hline $\begin{array}{l}\text { Job } \\
\text { application-to-open } \\
\text { ing ratio (March) }\end{array}$ & $\begin{array}{l}\text { 1974-2009: } \\
\text { monthly level }\end{array}$ & 0.839 & 0.475 & $\begin{array}{l}\text { Job/employment placement services statistics, } \\
\text { available at } \\
\text { http://www.e-stat.go.jp/SG1/estat/List.do?lid= } \\
\frac{000001108017}{2013)} \text { (last accessed March 11, }\end{array}$ \\
\hline
\end{tabular}


Table G: Blinder-Oaxaca decomposition of the estimates

\begin{tabular}{|c|c|c|c|c|c|c|c|}
\hline & \multirow[b]{2}{*}{ Year } & \multicolumn{2}{|c|}{ Fraction } & \multicolumn{2}{|c|}{ Estimates } & \multicolumn{2}{|c|}{ Decomposition } \\
\hline & & $W^{A}$ & $W^{B}$ & $\beta^{A}$ & $\beta^{B}$ & Explained & Unexplained \\
\hline \multirow[t]{8}{*}{ Mother's age } & & $<30$ & $>=30$ & $<30$ & $>=30$ & & \\
\hline & 1975 & 0.80 & 0.20 & 0.23 & 0.26 & - & - \\
\hline & 1980 & 0.71 & 0.29 & 0.25 & 0.14 & $48 \%$ & $52 \%$ \\
\hline & 1985 & 0.67 & 0.33 & 0.20 & 0.11 & $20 \%$ & $80 \%$ \\
\hline & 1990 & 0.63 & 0.37 & 0.13 & 0.09 & $5 \%$ & $95 \%$ \\
\hline & 1995 & 0.59 & 0.41 & 0.20 & 0.15 & $20 \%$ & $80 \%$ \\
\hline & 2000 & 0.55 & 0.45 & 0.13 & 0.07 & $11 \%$ & $89 \%$ \\
\hline & 2005 & 0.45 & 0.55 & 0.10 & 0.04 & $13 \%$ & $87 \%$ \\
\hline \multirow[t]{8}{*}{ Parity } & & $1 \mathrm{st}$ & $2 n d>$ & $1 \mathrm{st}$ & $2 n d>$ & & \\
\hline & 1975 & 0.44 & 0.56 & 0.18 & 0.28 & - & - \\
\hline & 1980 & 0.42 & 0.58 & 0.14 & 0.26 & $-14 \%$ & $114 \%$ \\
\hline & 1985 & 0.43 & 0.57 & 0.13 & 0.21 & $-2 \%$ & $102 \%$ \\
\hline & 1990 & 0.45 & 0.55 & 0.06 & 0.16 & $1 \%$ & $99 \%$ \\
\hline & 1995 & 0.49 & 0.51 & 0.16 & 0.19 & $3 \%$ & $98 \%$ \\
\hline & 2000 & 0.50 & 0.50 & 0.11 & 0.09 & $-1 \%$ & $101 \%$ \\
\hline & 2005 & 0.48 & 0.52 & 0.07 & 0.07 & $0 \%$ & $100 \%$ \\
\hline \multirow[t]{8}{*}{ Gender of child } & & female & male & female & male & & \\
\hline & 1975 & 0.49 & 0.51 & 0.21 & 0.26 & - & - \\
\hline & 1980 & 0.48 & 0.52 & 0.21 & 0.22 & $0 \%$ & $100 \%$ \\
\hline & 1985 & 0.48 & 0.52 & 0.16 & 0.19 & $0 \%$ & $100 \%$ \\
\hline & 1990 & 0.49 & 0.51 & 0.10 & 0.13 & $0 \%$ & $100 \%$ \\
\hline & 1995 & 0.48 & 0.52 & 0.17 & 0.19 & $0 \%$ & $100 \%$ \\
\hline & 2000 & 0.49 & 0.51 & 0.08 & 0.12 & $0 \%$ & $100 \%$ \\
\hline & 2005 & 0.49 & 0.51 & 0.03 & 0.10 & $0 \%$ & $100 \%$ \\
\hline \multirow[t]{8}{*}{ Working Status } & & non-working & working & non- working & working & & \\
\hline & 1975 & 0.80 & 0.20 & 0.21 & 0.34 & - & - \\
\hline & 1980 & 0.76 & 0.24 & 0.21 & 0.24 & $-7 \%$ & $107 \%$ \\
\hline & 1985 & 0.77 & 0.23 & 0.17 & 0.20 & $-2 \%$ & $102 \%$ \\
\hline & 1990 & 0.76 & 0.24 & 0.14 & 0.05 & $3 \%$ & $97 \%$ \\
\hline & 1995 & 0.77 & 0.23 & 0.21 & 0.09 & $8 \%$ & $92 \%$ \\
\hline & 2000 & 0.76 & 0.24 & 0.12 & 0.04 & $3 \%$ & $97 \%$ \\
\hline & 2005 & 0.59 & 0.41 & 0.46 & -0.47 & $129 \%$ & $-29 \%$ \\
\hline \multirow[t]{8}{*}{ Type of job } & & high-paid & low-paid & high-paid & low-paid & & \\
\hline & 1975 & 0.61 & 0.39 & 0.31 & 0.40 & - & - \\
\hline & 1980 & 0.67 & 0.33 & 0.31 & 0.09 & $-14 \%$ & $114 \%$ \\
\hline & 1985 & 0.72 & 0.28 & 0.30 & -0.05 & $-28 \%$ & $128 \%$ \\
\hline & 1990 & 0.68 & 0.32 & 0.32 & -0.50 & $-20 \%$ & $120 \%$ \\
\hline & 1995 & 0.69 & 0.31 & 0.45 & -0.67 & $-40 \%$ & $140 \%$ \\
\hline & 2000 & 0.67 & 0.33 & 0.44 & -0.72 & $-24 \%$ & $124 \%$ \\
\hline & 2005 & 0.42 & 0.58 & 0.48 & -1.23 & $37 \%$ & $63 \%$ \\
\hline
\end{tabular}

Note: The base year in decomposition is 1975 . The minus sign in decomposition indicates that the compositional change of mothers predicts the opposite sign as the sign of the change in the estimates $\left(\beta_{1}-\beta_{0}\right)$. 